\title{
Improvement of cooling performance of hybrid nanofluids in a heated pipe applying annular magnets
}

\author{
Guolong $\mathrm{Li}^{1} \cdot$ Jin Wang ${ }^{1} \cdot$ Hongxing Zheng ${ }^{1} \cdot$ Gongnan $\mathrm{Xie}^{2} \cdot$ Bengt Sundén $^{3}$
}

Received: 21 December 2020 / Accepted: 13 April 2021 / Published online: 20 May 2021

(c) The Author(s) 2021

\begin{abstract}
In this paper, convective heat transfer of $\mathrm{Fe}_{3} \mathrm{O}_{4}$-carbon nanotubes (CNTs) hybrid nanofluid was studied in a horizontal small circular tube under influence of annular magnets. The pipe has an inner diameter of $3 \mathrm{~mm}$ and a length of $1.2 \mathrm{~m}$. Heat transfer characteristics of the $\mathrm{Fe}_{3} \mathrm{O}_{4}$-water nanofluid were examined for many parameters, such as nanoparticle volume fraction in the range of $0.4-1.2 \%$ and Reynolds number in the range of 476-996. In order to increase the thermal conductivity of the $\mathrm{Fe}_{3} \mathrm{O}_{4}$-water nanofluid, carbon nanotubes with $0.12-0.48 \%$ volume fraction were added into the nanofluid. It was observed that for the $\mathrm{Fe}_{3} \mathrm{O}_{4}-\mathrm{CNTs}$-water nanofluid with $1.44 \%$ volume fraction and under a magnetic field, the maximal local Nusselt number at the Reynolds number 996 increased by $61.54 \%$ compared with without a magnetic field. Results also show that compared with the deionized water, the maximal enhancements of the average Nusselt number are 67.9 and $20.89 \%$ for the $\mathrm{Fe}_{3} \mathrm{O}_{4}-\mathrm{CNTs}-$ water nanofluid with and without magnetic field, respectively.
\end{abstract}

Keywords Magnetic nanofluid · Ferrofluid · Convective heat transfer $\cdot$ Carbon nanotube $\cdot$ Magnetic field

$\begin{array}{ll}\text { Abbreviations } \\ B & \text { Magnetic flux density, } \mathrm{T} \\ B_{\mathrm{r}} & \text { Remnant magnetic flux density, } \mathrm{T} \\ c_{\mathrm{p}} & \text { Specific heat at constant pressure, } \mathrm{J} \mathrm{kg}^{-1} \mathrm{~K}^{-1} \\ D & \text { Diameter, } \mathrm{m} \\ F & \text { Force, } \mathrm{N} \\ h & \text { Local heat transfer coefficient, } \mathrm{W} \mathrm{m}^{-2} \mathrm{~K}^{-1} \\ H & \text { Magnetic field, } \mathrm{A} \mathrm{m} \\ I & \text { Current, A }\end{array}$

Jin Wang

wjwcn00@163.com

$\triangle$ Bengt Sundén

bengt.sunden@energy.lth.se

Guolong Li

long1812190184@163.com

Hongxing Zheng

hxzheng@hebut.edu.cn

Gongnan Xie

xgn@nwpu.edu.cn

1 School of Energy and Environmental Engineering, Hebei University of Technology, Tianjin 300401, China

2 School of Marine Science and Technology, Northwestern Polytechnical University, Xi' an 710072, China

3 Department of Energy Sciences, Division of Heat Transfer, Lund University, 22100 Lund, Sweden $k \quad$ Thermal conductivity, $\mathrm{W} \mathrm{m}^{-1} \mathrm{~K}^{-1}$

$k_{\mathrm{w}} \quad$ Thermal conductivity of stainless steel, $\mathrm{W} \mathrm{m}{ }^{-1} \mathrm{~K}^{-1}$

$L \quad$ Length, m

$\mathrm{Nu}$ Nusselt number

Pr Prandtl number

$Q \quad$ Flow rate, $\mathrm{m}^{3} \mathrm{~s}^{-1}$

$q^{\prime \prime} \quad$ Heat flux based on thermal power, $\mathrm{W} \mathrm{m}^{-2}$

$q \quad$ Thermal power, $\mathrm{W}$

Re Reynolds number

$T$ Temperature, $\mathrm{K}$

$U \quad$ Velocity, $\mathrm{m} \mathrm{s}^{-1}$

$V \quad$ Voltage, $\mathrm{V}$

$x \quad$ Axial distance from the entrance, $\mathrm{m}$

\section{Greek symbols}

$\alpha \quad$ Thermal efficiency

$\eta \quad$ Heat transfer enhancement percentage in comparison with distilled water, \%

$\mu \quad$ Dynamic viscosity, Pa s

$\mu_{0} \quad$ Permeability of free space, $\mathrm{N} \mathrm{A}^{-2}$

$\mu_{\mathrm{r}} \quad$ Relative permeability

$\rho \quad$ Density, $\mathrm{kg} \mathrm{m}^{-3}$

$\varphi \quad$ Nanoparticle volume fraction

$\chi_{\mathrm{i}} \quad$ Magnetic susceptibility

\section{Subscripts}

avg Average

b Bulk 


$\begin{array}{ll}\text { bf } & \text { Base fluid } \\ \text { ff } & \text { Ferrofluid } \\ \text { in } & \text { Inlet } \\ \text { i } & \text { Inside } \\ \text { M } & \text { Magnetic } \\ \text { out } & \text { Outlet } \\ \text { o } & \text { Outside } \\ \text { p } & \text { Particle }\end{array}$

\section{Introduction}

With increasing serious problems of global environmental pollution and energy shortages, energy conservation and environmental protection have become important themes of common concern in the world. Heat transfer efficiency in heat exchange systems is needed to be enhanced to effectively save energy. However, traditional fluids have low thermal conductivity, which is difficult to meet heat transfer requirements under some special conditions. One focus of heat transfer studies is how to find a novel heat transfer fluid to replace the traditional fluid for the improvement of the heat transfer efficiency. In the past 20 years, numerous researchers have studied heat transfer characteristics of various nanofluids. Usually, the nanofluid shows significant improvement in heat transfer performance of conventional fluids water, glycol, oil, and etc. Ali et al. [1] performed heat transfer performance of $\mathrm{ZnO}$-water nanofluid in a car radiator with ranges of Reynolds numbers, volume fractions, and inlet temperatures of 7500-27,600, $0.01-0.3 \%$ and $45-55{ }^{\circ} \mathrm{C}$, respectively. Results indicated that when the volume fraction of the nanofluid was $0.2 \%$, the heat transfer performance of the car radiator was $46 \%$ higher than base fluid. Sajid et al. [2] studied heat transfer of a mini-channel heat sinks filled with $\mathrm{TiO}_{2}$-water nanofluid. Results indicated that $0.012 \mathrm{vol} \% \mathrm{TiO}_{2}$-water nanofluid showed a maximum enhancement of $40.57 \%$ in Nusselt number compared to water at $\mathrm{Re}=894$. Ebrahimi et al. [3] investigated heat transfer performance of $\mathrm{Al}_{2} \mathrm{O}_{3}$-water and $\mathrm{CuO}$-water nanofluids in a rectangular microchannel heat sink by changing nanoparticle volume fractions, sizes and Reynolds numbers. They found that heat transfer efficiency and pressure loss of $\mathrm{CuO}$-water nanofluid was higher than those of $\mathrm{Al}_{2} \mathrm{O}_{3}$-water nanofluid at the same conditions. Shanbedi et al. [4] examined the thermal conductivity of multi-walled carbon nanotubes-water nanofluid. Their results demonstrated that the thermal conductivity of the metal nanoparticles-decorated carbon nanotubes nanofluid was higher than that of gum Arabic decorated carbon nanotubes nanofluid. Zheng et al. [5] investigated effects of magnetic fields on flow characteristics and thermal performance of a plate heat exchanger filled with a magnetic nanofluid. They found that appropriate magnet arrangement resulted in good thermal performance and low flow resistance simultaneously. Kumar and Chandrasekar [6] analyzed heat transfer performance of multiwall carbon nanotube-water nanofluids in a double helically coiled tube heat exchanger, and they found that $35 \%$ heat transfer was enhancement is obtained for the 0.6 vol.\% MWCNT-water nanofluid at a Dean number of 1200. Dabiri et al. [7] experimentally studied heat transfer characteristics of $\mathrm{SiC}$-water and $\mathrm{MgO}$-water nanofluids inside a circular tube. Results showed that an increase in heat transfer enhancement was observed by increasing volume concentration and Reynolds number. Sarafraz et al. [8] experimentally investigated convective heat transfer of carbon nanotube-water nanofluid inside a double pipe heat exchanger, and their results revealed that by adding 0.3 mass\% carbon nanotubes into the base fluid, the thermal conductivity was enhanced by at most $56 \%$. Hosseinipour et al. [9] investigated the effect of surfactants on heat transfer and pressure drop of multi-walled carbon nanotubes (MWCNT)-water nanofluids in a circular tube. They found that the MWCNT- water nanofluid with arginine showed better heat transfer performance than that with gum Arabic at the same concentrations.

Magnetic nanofluids have been widely used in different fields, such as thermal engineering [10] (heat exchanger, solar collector, air conditioning system, etc.), bioengineering and optical [11] and sealing technology. The magnetic nanofluid has remarkable potential for heat transfer applications because heat transfer process can be controlled by varying the strength and orientation of the magnetic field. Wang et al. [12] showed a large enhancement in convective heat transfer by using $\mathrm{Fe}_{3} \mathrm{O}_{4}$-water nanofluid in a stainless steel pipe under a permanent magnetic field. $\mathrm{Fe}_{3} \mathrm{O}_{4}$-water nanofluid with a magnetic cannula showed heat transfer enhancements of $26.5 \%$ and $54.5 \%$ at $\operatorname{Re}=391$ and 805 , respectively. Hosseinzadeh et al. [13] analyzed heat transfer and friction factor of $\mathrm{Fe}_{3} \mathrm{O}_{4}$-water nanofluids in a horizontal circular tube under a magnetic field. It was observed that a heat transfer enhancement of $15.43 \%$ was obtained by applying a magnetic field (200 G). Goharkhah et al. [14] analyzed heat transfer and pressure drop of $\mathrm{Fe}_{3} \mathrm{O}_{4}$-water nanofluid in a parallel plate channel under an alternating magnetic field. They observed that the maximum heat transfer enhancement of $37.34 \%$ was attained by application of alternating magnetic field. Asfer et al. [15] studied heat transfer characteristics of a magnetic nanofluid in a circular pipe. They found that increasing the gradient of the magnetic field improved heat transfer. Li and Xuan [16] studied the heat transfer characteristics of magnetic nanofluids exposed to a magnetic field. They concluded that applying a uniform magnetic field opposite to the flow direction reduced the heat transfer coefficient of the magnetic nanofluid.

Hybrid nanofluids are prepared by dispersing various types of nanoparticles into a base fluid. It is found that 
hybrid nanofluids show enhancements of heat transfer performance and improvements of thermophysical properties compared with conventional fluids. Many scholars numerically and experimentally carried out heat transfer analysis of hybrid ferrofluids under an external magnetic field. Shahsavar et al. [17] investigated heat transfer in a heated pipe filled with a $\mathrm{Fe}_{3} \mathrm{O}_{4}$-carbon nanotubes (CNTs) hybrid nanofluid. They concluded that $0.5 \mathrm{vol} \% \mathrm{Fe}_{3} \mathrm{O}_{4}$ and 1.35 vol\% CNTs hybrid nanofluid showed a maximum enhancement of $62.7 \%$ in the local Nusselt number, compared with water at $\mathrm{Re}=2190$. Harandi et al. [18] analyzed the thermal conductivity of $\mathrm{Fe}_{3} \mathrm{O}_{4}$-carbon nanotubes-ethylene glycol (EG) hybrid nanofluid, and found that the thermal conductivity of the nanofluid was enhanced by $30 \%$ at $50{ }^{\circ} \mathrm{C}$ and $2.3 \%$ volume fraction. Askari et al. [19] investigated thermal characteristics of a $\mathrm{Fe}_{3} \mathrm{O}_{4}$-graphene nanofluid. It was observed that compared to the base fluid, the thermal conductivity of the nanofluid was enhanced up to $32 \%$ at $1 \%$ mass fraction and $50{ }^{\circ} \mathrm{C}$. Askari et al. [20] measured the effect of hybrid $\mathrm{Fe}_{3} \mathrm{O}_{4}$-graphene nanoparticles on the thermal conductivity of water. Results revealed that a maximum increase of $31 \%$ of the thermal conductivity was achieved for 1 mass $\%$ nanoparticle concentration at $50{ }^{\circ} \mathrm{C}$. Nadooshan et al. [21] examined the viscosity of $\mathrm{Fe}_{3} \mathrm{O}_{4}$-MWCNTs-ethylene glycol hybrid nanofluid in a temperature range of $25-50{ }^{\circ} \mathrm{C}$ and various solid volume fractions $(0.1,0.25,0.8,1.25$ and $1.8 \%)$. Results showed that the examined hybrid nanofluid exhibited a Newtonian behavior, and higher volume fraction of the nanofluid resulted in higher viscosity. Farbod and Ahangarpour [22] investigated thermal conductivity of a MWCNTs-Ag-water nanofluid in a temperature range of $20-50{ }^{\circ} \mathrm{C}$. It was found that compared with the MWCNTs-water nanofluid, the MWCNTs-Ag-water nanofluid with $4 \% \mathrm{Ag}$ had a maximum enhancement of $20.4 \%$ in thermal conductivity.

The available studies on the heat transfer performance of the magnetic nanofluids have mainly focused on a single species of particles under a magnetic field. This means that the existing experimental data is insufficient for evaluation of heat transfer performance of hybrid magnetic nanofluids in a heat transfer system. This paper aims to investigate laminar convective heat transfer of $\mathrm{Fe}_{3} \mathrm{O}_{4}$-water and $\mathrm{Fe}_{3} \mathrm{O}_{4}-\mathrm{CNTs}$-water nanofluids in a straight stainless steel pipe in presence of a magnetic field. Effects of the layout of magnets, Reynolds number and nanoparticle volume fraction on heat transfer characteristics of various nanofluids are analyzed by the experimental tests.

\section{Experimental}

\section{Particle characterization, ferrofluid preparation and stability}

In the present research, $\mathrm{Fe}_{3} \mathrm{O}_{4}$ nanoparticles were prepared by chemical coprecipitation method, and multi-wall carbon nanotubes (MWCNTs) were provided by Chengdu Organic Chemicals Co. Ltd., Chinese Academy of Sciences. These CNTs have a true density of $2.1 \mathrm{~g} \mathrm{~cm}^{-3}$ [21], outer diameter of 8-15 nm, with a purity of more than $99.9 \%$. Using transmission electron microscopy (TEM) and scanning electron microscopy (SEM), micrographs of the nanoparticles $\mathrm{Fe}_{3} \mathrm{O}_{4}$ and CNTs are shown in Fig. 1. It is observed that the nanoparticle $\mathrm{Fe}_{3} \mathrm{O}_{4}$ has an average diameter of $15 \pm 5 \mathrm{~nm}$.

The photographs of $\mathrm{Fe}_{3} \mathrm{O}_{4}$-water and $\mathrm{Fe}_{3} \mathrm{O}_{4}$-CNTs-water nanofluids are provided in Fig. 2. Carbon nanotubes (CNTs) were chemically functionalized by potassium persulfate solution with $\mathrm{pH}=13$ at $85^{\circ} \mathrm{C}$. CNTs and surfactants were weighed by an electronic balance. The CNTs with surfactants were mixed into distilled water. The mixed solution was stirred by a mechanical stirrer at $1500 \mathrm{r} \mathrm{min}^{-1}$ and dispersed by an ultrasonic cleaner for $60 \mathrm{~min}$. The power and frequency of the ultrasonic cleaner were $380 \mathrm{~W}$ and $40 \mathrm{kHz}$, respectively. $\mathrm{Fe}_{3} \mathrm{O}_{4}$ magnetic nanoparticles and trisodium
Fig. 1 Images of two nanoparticles using TEM and SEM

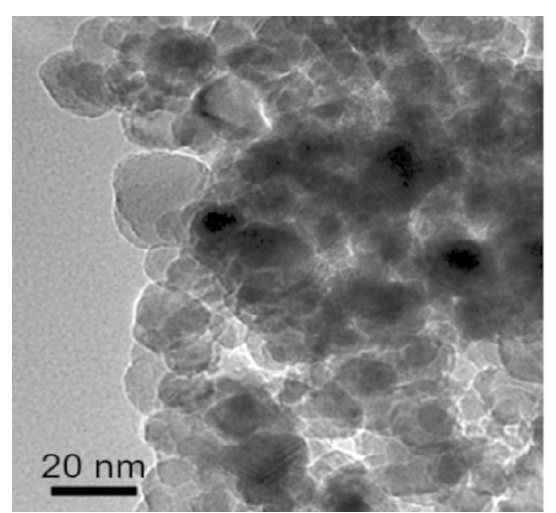

(a) $\mathrm{Fe}_{3} \mathrm{O}_{4}$ nanoparticles

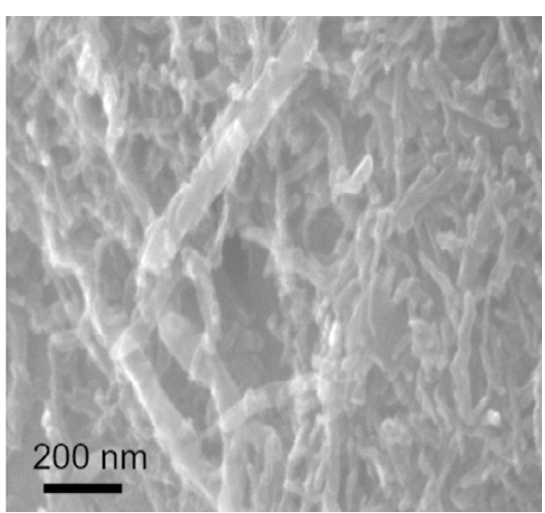

(b) $\mathrm{CNTs}$ 
Fig. 2 Real photographs of nanofluids

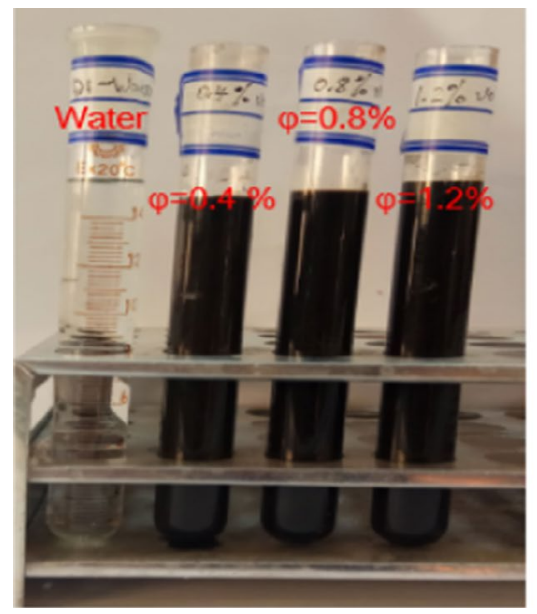

(a) $\mathrm{Fe}_{3} \mathrm{O}_{4}$-water nanofluid

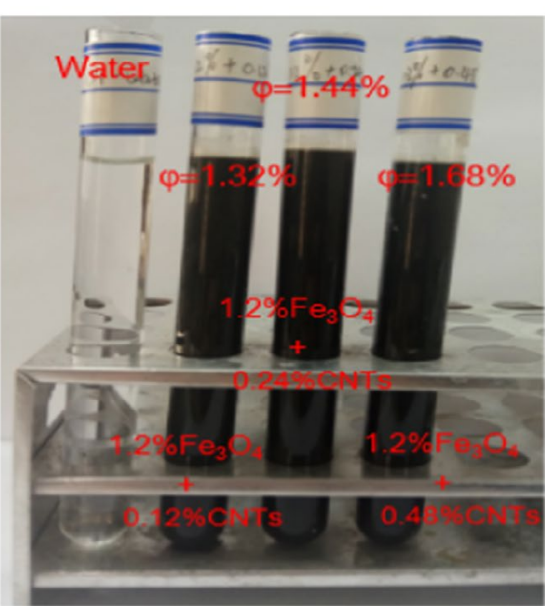

(b) $\mathrm{Fe}_{3} \mathrm{O}_{4}$-CNTs-water nanofluid citrate dehydrate (TSC) with a ratio of 8:1 were used to synthesize a magnetic nanofluid. The CNTs and Arabic gum with a mass ratio of 5:1 were dispersed into the $\mathrm{Fe}_{3} \mathrm{O}_{4}$-water nanofluid. Zeta potentials of samples were measured using a ZS-90 zeta potential analyzer (Malvern Co., Ltd., UK). The stability of the nanofluid can be evaluated by measuring the zeta potential of the nanofluid. When the zeta potential value of the nanofluid is higher than $30 \mathrm{mV}$, it is considered that the nanofluid has a better stability. The zeta potentials of the $1.2 \% \mathrm{Fe}_{3} \mathrm{O}_{4}$-water and $1.32 \% \mathrm{Fe}_{3} \mathrm{O}_{4}$-CNTs-water nanofluids are $-31.6 \pm 7.4 \mathrm{mV}$ and $-30.8 \pm 6.94 \mathrm{mV}$, respectively, which indicate that these nanofluids have good dispersion stability. Sedimentation of nanoparticles is investigated in a silicone pipe with a length of $20 \mathrm{~cm}$, an outer diameter of $5 \mathrm{~mm}$, and an inner diameter of $3 \mathrm{~mm}$. The $1.2 \%$ $\mathrm{Fe}_{3} \mathrm{O}_{4}$-water and $1.44 \% \mathrm{Fe}_{3} \mathrm{O}_{4}-\mathrm{CNT}$-water nanofluids are kept at experimental operation for two hours. In order to obtain high accuracy of the experimental data, the tests are repeated 5 times. For the $1.2 \% \mathrm{Fe}_{3} \mathrm{O}_{4}$-water and $1.44 \%$ $\mathrm{Fe}_{3} \mathrm{O}_{4}-\mathrm{CNT}$-water nanofluids, the mass of the silicone tube before and after the tests increased by 0.12 and $0.13 \%$ (average value) respectively. The results reveal that a little sedimentation appears for the $\mathrm{Fe}_{3} \mathrm{O}_{4}-\mathrm{CNT}$-water nanofluid during the tests. Figure 3 presents the zeta potential distributions of the two nanofluids. Table 1 shows density $(\rho)$, thermal conductivity $(k)$, dynamic viscosity $(\mu)$ and specific heat $\left(C_{\mathrm{p}}\right)$ of the base fluid and nanoparticles.

Viscosities of the nanofluids are obtained using a Brookfield DV2T viscometer. According to Fig. 4, it is revealed that the viscosity is directly proportional to the volume concentration of nanoparticles. Compared with distilled water, the average viscosity of 1.68 vol\% $\mathrm{Fe}_{3} \mathrm{O}_{4}-\mathrm{CNTs}-$ water nanofluid is increased by $109.6 \%$. Figure 5 shows the viscosity of the two nanofluids as a function of shear rate at $25^{\circ} \mathrm{C}$. The viscosities of the
$\mathrm{Fe}_{3} \mathrm{O}_{4}$-water nanofluid and the deionized fluid are almost

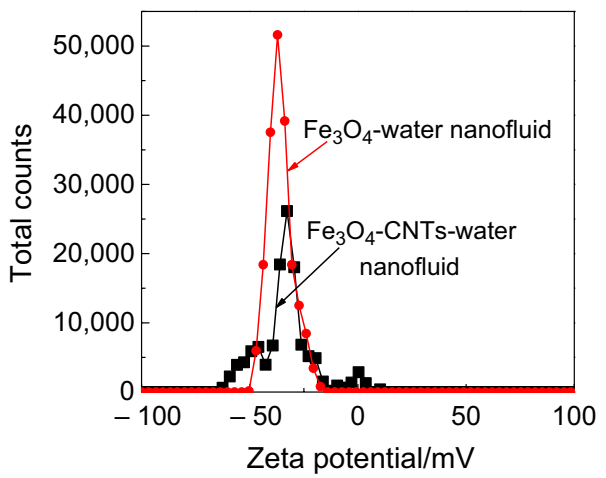

Fig. 3 Zeta potential distributions

Table 1 Physical properties of the base fluid and nanoparticles at $25^{\circ} \mathrm{C}$

\begin{tabular}{llllc}
\hline & $\rho / \mathrm{kg} \mathrm{m}^{-3}$ & $C_{\mathrm{p}} / \mathrm{J} \mathrm{kg}^{-1} \mathrm{~K}^{-1}$ & $k / \mathrm{W} \mathrm{m}^{-1} \mathrm{~K}^{-1}$ & $\mu / \mathrm{Pa} \mathrm{s}$ \\
\hline DI-water & 997 & 4180 & $0.6 \pm 0.012$ & 0.0009 \\
$\mathrm{Fe}_{3} \mathrm{O}_{4}$ & 5180 & 670 & 80 & - \\
$\mathrm{CNTs}$ & 2100 & 425 & $3000[21]$ & - \\
\hline
\end{tabular}

constant with increasing shear rate, which indicates a Newtonian fluid behavior For the $\mathrm{Fe}_{3} \mathrm{O}_{4}-\mathrm{CNTs}-$ water nanofluid, an increase of the shear rate results in a reduction of the viscosity, showing a non-Newtonian behavior of shear thinning. Generally, it is considered that the shear thinning behavior is caused due to a reduction of suspended particle clusters under shear force. 


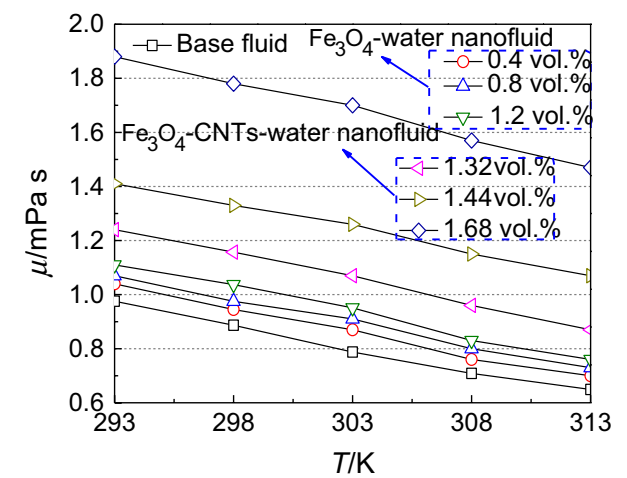

Fig. 4 Dynamic viscosity of various nanofluids as function of temperature (shear rate of $73.38 \mathrm{~s}^{-1}$ )

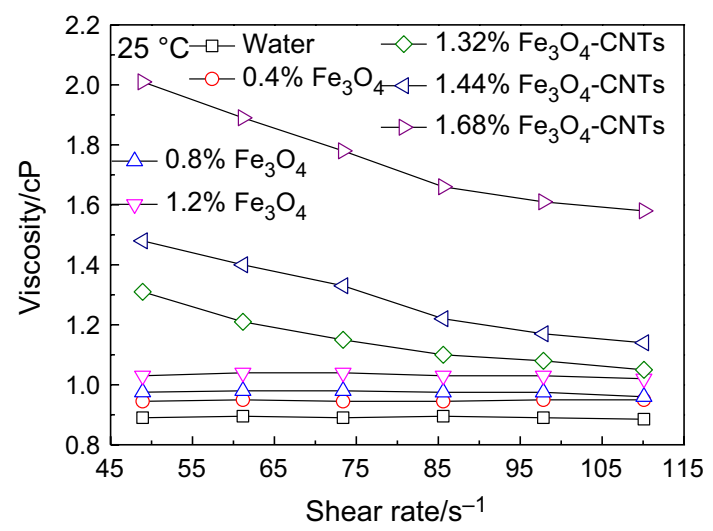

Fig. 5 Dynamic viscosity of nanofluids as function of shear rate

\section{Apparatus}

Figure 6 shows a schematic and physical diagram of the experimental system, which consists of a pump, a flow meter, a heat exchanger, a thermostatic bath, and a test section. The test section is a straight stainless steel pipe with a length of $1.2 \mathrm{~m}$, an inner diameter of $3 \mathrm{~mm}$, and an outer diameter of $4 \mathrm{~mm}$. Wall temperature on the pipe is measured by nine T-type thermocouples with a diameter of $0.3 \mathrm{~mm}$. The bulk temperatures at inlet and outlet of the test section are measured by two T-type armored thermocouples with a diameter of $1 \mathrm{~mm}$. The temperature measurements of the mercury thermometer (accuracy of $0.1^{\circ} \mathrm{C}$ ) are used to calibrate the thermocouples. Uncertainty of temperature measurements after calibration is $0.1^{\circ} \mathrm{C}$. The thermocouple wires are directly welded on the test section to avoid any thermal resistance between thermocouples and test section. Temperature values are monitored by thermocouples connected to a 20-channel data acquisition unit. A constant heat flux for the pipe is supplied by a DC power of $0-150 \mathrm{~W}$. The test section is wrapped with thermal insulation materials to minimize heat losses. A gear pump (WT3000-1JA) is used to circulate the nanofluid. In order to measure the flow rate, a turbine flowmeter of Titan 803 (Beijing Dongfang New Power Mechanical \& Electrical Equipment Co., Ltd.) with a flow rate range of $0.05-0.5 \mathrm{~L} \mathrm{~min}^{-1}$ is installed downstream the pump. The flowmeter is calibrated by weighing with a high-precision electronic balance. After calibration, the uncertainty of the flowmeter is $1 \%$. A thermostatic bath maintains a constant inlet temperature of the fluid. A simple copper coil pipe cools down the outflow fluid downstream the test section.

\section{Magnet arrangement}

Geometry information of magnets and cannulas are presented in Fig. 7. Forced convective heat transfer in the pipe is investigated by changing the number of the magnets as in the previous research [12]. The cannulas are used to generate various magnetic fields perpendicular to the

Fig. 6 The used experimental system

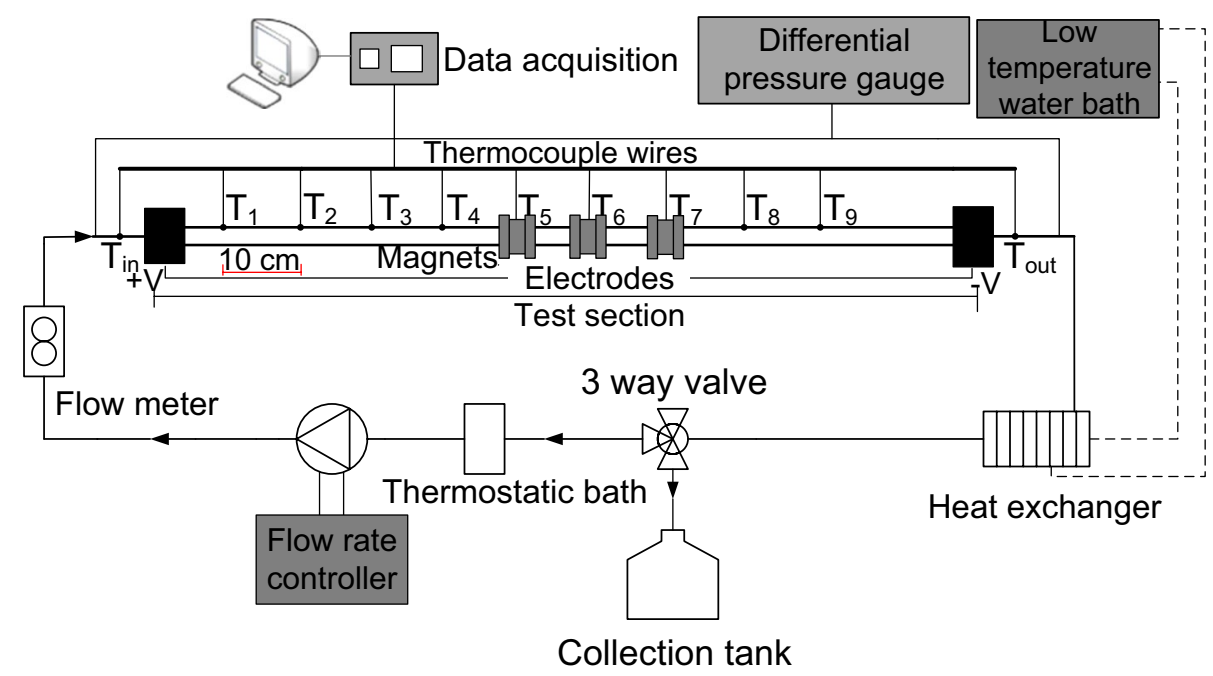


Fig. 7 Dimensions of a cannula $(\mathrm{mm})$

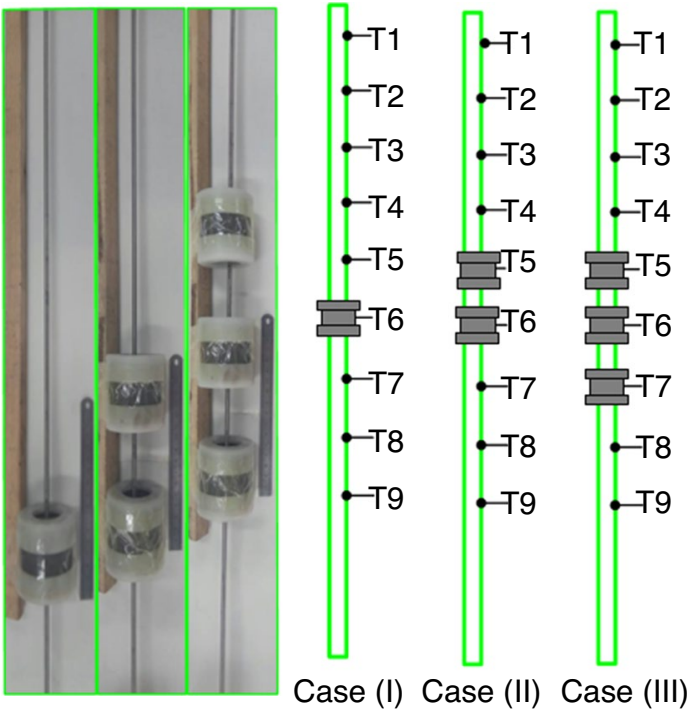

Fig. 8 Three magnet arrangements

Table 2 Data of permanent magnets

\begin{tabular}{ll}
\hline Parameters & Description \\
\hline Magnetic type & NdFeB (Neodymium) N42 \\
Maximum operating temperature & $80{ }^{\circ} \mathrm{C}$ \\
Surface field & $0.3332 \mathrm{~T}$ \\
Residual flux density $\left(B_{\mathrm{rmax}}\right)$ & $1.32 \mathrm{~T}$ \\
Maximum energy product $\left(B_{\mathrm{Hmax}}\right)$ & $42 \mathrm{MGOe}$ \\
Relative permeability $\left(\mu_{\mathrm{r}}\right)$ & 1.05 \\
Magnetic permeability of free space $\left(\mu_{0}\right)$ & $4 \pi \times 10^{-7} \mathrm{~N} \mathrm{~A}^{-2}$ \\
\hline
\end{tabular}

test section. Figure 8 shows three arrangements of cannulas under non-uniform permanent magnetic fields, i.e., case I, case II and case III. Data of the magnets is summarized in Table 2.

\section{Analysis of experimental data}

Nusselt number $(\mathrm{Nu})$ is defined by:

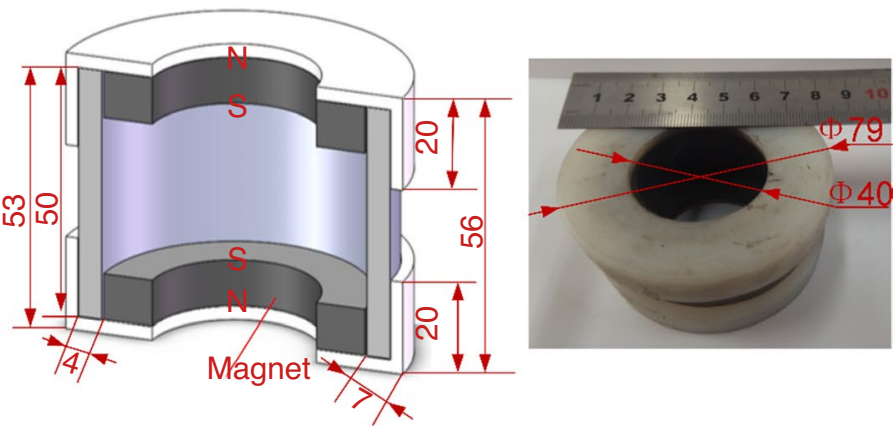

$\mathrm{Nu}=\frac{h D_{\mathrm{i}}}{k}$

where $k$ is thermal conductivity of the fluid at $25^{\circ} \mathrm{C} . D_{\mathrm{i}}$ is inner diameter of a stainless steel pipe. $h$ in Eq. (1) is the local heat transfer coefficient and calculated as:

$h=\frac{q^{\prime \prime}}{T_{\mathrm{w}, \mathrm{i}}(x)-T_{\mathrm{b}}(x)}$

where the variable $x$ is the axial distance from the inlet of the stainless steel pipe, and $q^{\prime \prime}$ is the heat flux. The fluid temperature $T_{\mathrm{b}}(x)$ is obtained by the following equation:

$T_{\mathrm{b}}(x)=\frac{q^{\prime \prime} \pi D_{\mathrm{o}}}{\rho Q C_{\mathrm{p}}} x+T_{\mathrm{in}}$

where $Q$ and $\rho$ are volume flow rate and density of the working fluid, respectively. Due to the small inner diameter (3 $\mathrm{mm}$ ) and a uniform heating of the pipe, the wall heat conduction along the axial direction is ignored and the heat conduction in the circumferential direction is uniform. Therefore, the heat conduction in the tube wall is approximated as a one-dimensional heat transfer problem with an internal heat source along the radial direction. The inner wall temperature $T_{\mathrm{w}, \mathrm{i}}(x)$ is given by:

$T_{\mathrm{w}, \mathrm{i}}(x)=T_{\mathrm{w}, \mathrm{o}}(x)-\frac{\alpha V I}{2 \pi K_{\mathrm{w}} L}\left[\frac{D_{\mathrm{o}}^{2}}{D_{\mathrm{o}}^{2}-D_{\mathrm{i}}^{2}} \log \left(\frac{D_{\mathrm{o}}}{D_{\mathrm{i}}}-0.5\right)\right]$

where $K_{\mathrm{w}}$ and $D_{\mathrm{o}}$ are thermal conductivity and outer diameter of the stainless steel pipe, respectively.

The heat flux $q^{\prime \prime}$ is calculated as:

$q^{\prime \prime}=\frac{\alpha V I}{\pi D_{0} L}$

where $L$ is the length of the stainless steel pipe. $I$ and $V$ are the given current and voltage, respectively. Based on a series of thermal equilibrium tests using deionized water, the thermal efficiency is determined to be $0.93 \pm 0.015$. The thermal efficiency $\alpha$ of the test section is calculated by: 
$\alpha=\frac{Q_{\mathrm{m}} c_{\mathrm{p}}\left(T_{\text {in }}-T_{\text {out }}\right)}{V I}$

where $Q_{\mathrm{m}}$ is the mass flow rate. The density $\rho_{\text {ff }}$, specific heat $C_{\mathrm{p} \text {,ff }}$ and thermal conductivity $k_{\mathrm{ff}}$ of the hybrid nanofluid are calculated as shown in Ref. [23]:

$\rho_{\mathrm{ff}}=\varphi_{1} \rho_{1}+\varphi_{2} \rho_{2}+(1-\varphi) \rho_{\mathrm{bf}}$

$\left(\rho c_{\mathrm{p}}\right)_{\mathrm{ff}}=\varphi_{1}\left(\rho c_{\mathrm{p}}\right)_{1}+\varphi_{2}\left(\rho c_{\mathrm{p}}\right)_{2}+(1-\varphi)\left(\rho c_{\mathrm{p}}\right)_{\mathrm{bf}}$

$\frac{k_{\mathrm{ff}}}{k_{\mathrm{bf}}}=\frac{\varphi_{1} k_{1}+\varphi_{2} k_{2}+2 \varphi k_{\mathrm{bf}}+2 \varphi\left(\varphi_{1} k_{1}+\varphi_{2} k_{2}\right)-2 \varphi^{2} k_{\mathrm{bf}}}{\varphi_{1} k_{1}+\varphi_{2} k_{2}+2 \varphi k_{\mathrm{bf}}-\varphi\left(\varphi_{1} k_{1}+\varphi_{2} k_{2}\right)+\varphi^{2} k_{\mathrm{bf}}}$

The viscosity of the hybrid nanofluid $\left(\mu_{\mathrm{ff}}\right)$ is obtained as follows [24]:

$\mu_{\mathrm{ff}}=\mu_{\mathrm{bf}}(1+2.5 \varphi)$

The total volume concentration $(\varphi)$ of nanoparticles $\mathrm{Fe}_{3} \mathrm{O}_{4}$ and CNTs is obtained by:

$\varphi=\varphi_{1}+\varphi_{2}$

where subscripts $1,2, \mathrm{p}$ and bf represent physical properties of the $\mathrm{Fe}_{3} \mathrm{O}_{4}$-water nanofluid, CNTs-water nanofluid, nanoparticles and the base fluid, respectively.

To evaluate the enhancement of heat transfer by using the hybrid nanofluid, average $\mathrm{Nu}$ (based on measurements of 9 thermocouples on the test section) and the increased value of the average $\mathrm{Nu}$ are introduced as

$\mathrm{Nu}_{\mathrm{avg}}=\frac{\sum_{i=1}^{9} \mathrm{Nu}_{\mathrm{i}}}{9}$

Table 3 Uncertainties of the measured variables

\begin{tabular}{ll}
\hline Variable name & Uncertainty \\
\hline Voltage $(V)$ & \pm 0.003509 \\
Current $(I)$ & $\pm 5.749 \times 10^{-4}$ \\
Length $(L)$ & $\pm 8.333 \times 10^{-4}$ \\
Diameter $\left(D_{i}\right)$ & \pm 0.03333 \\
$T_{\text {out }}-T_{\text {in }}$ & \pm 0.03497 \\
$T_{\mathrm{w}, \mathrm{i}}-T_{\mathrm{b}}$ & \pm 0.07519 \\
Dynamic viscosity & \pm 0.01 \\
Volume flow $(Q)$ & \pm 0.01 \\
\hline
\end{tabular}

Max. $U_{\mathrm{R}}= \pm \sqrt{\left(\frac{s_{1}}{R} \frac{\partial R}{\partial s_{1}} U_{\mathrm{s}_{1}}\right)^{2}+\left(\frac{s_{2}}{R} \frac{\partial R}{\partial s_{2}} U_{\mathrm{x}_{2}}\right)^{2}+\cdots+\left(\frac{s_{\mathrm{n}}}{R} \frac{\partial R}{\partial s_{\mathrm{n}}} U_{\mathrm{S}_{\mathrm{n}}}\right)^{2}}$

where $U_{\mathrm{R}}$ is the maximum error of the parameter $R . s$ is measurable parameter, and $U_{s}$ is measured error. The maximum uncertainties of $\mathrm{V}, \mathrm{I}, \mathrm{q}, \mathrm{Re}, \mathrm{h}$ and $\mathrm{Nu}$ are determined by:

$U_{\mathrm{V}}= \pm \frac{0.1}{2.85}= \pm 0.03509$

$U_{\mathrm{I}}= \pm \frac{0.01}{18.25}= \pm 5.479 \times 10^{-4}$

Max. $U_{\mathrm{q}}= \pm \sqrt{\left(U_{\mathrm{I}}\right)^{2}+\left(U_{\mathrm{V}}\right)^{2}}= \pm 3.51 \%$

Max. $U_{\mathrm{Re}}= \pm \sqrt{\left(U_{\rho}\right)^{2}+\left(U_{Q}\right)^{2}+\left(U_{D_{i}}\right)^{2}+\left(U_{\mu}\right)^{2}}= \pm 3.62 \%$

Max. $U_{\mathrm{h}}= \pm \sqrt{\left(U_{C_{\mathrm{p}}}\right)^{2}+\left(U_{\rho}\right)^{2}+\left(U_{\mathrm{Q}}\right)^{2}+\left(U_{T_{\text {out }}-T_{\text {in }}}\right)^{2}+\left(U_{D_{i}}\right)^{2}+\left(U_{\mathrm{L}}\right)^{2}+\left(U_{T_{\mathrm{w}}-T_{\mathrm{b}}}\right)^{2}}= \pm 8.99 \%$

$\eta=\frac{\mathrm{Nu}_{\text {avg,ff }}-\mathrm{Nu}_{\text {avg,bf }}}{N u_{\text {avg,bf }}}$

\section{Uncertainty analysis}

Uncertainties of measurements are summarized in Table 3. The viscosity measurements (Brookfield DV2T viscometer) have an accuracy of $1 \%$. The accuracy of the thermocouples after calibration is $0.1{ }^{\circ} \mathrm{C}$. The voltage and current values used in the tests are $2.85 \pm 0.1 \mathrm{~V}$ and $18.25 \pm 0.01 \mathrm{~A}$, respectively. According to the uncertainty analysis of the experimental results described in Ref. [25], the maximum uncertainty of the parameter $R$ is calculated as
Max. $U_{\mathrm{Nu}}= \pm \sqrt{\left(U_{\mathrm{h}}\right)^{2}+\left(U_{D_{i}}\right)^{2}+\left(U_{\mathrm{k}}\right)^{2}}= \pm 9.59 \%$

Therefore, the uncertainties of $\mathrm{q}, \mathrm{Re}, \mathrm{h}$ and $\mathrm{Nu}$ are $\pm 3.51, \pm 3.62, \pm 8.99$, and $\pm 9.59 \%$, respectively.

\section{Results and discussion}

\section{Simulation analysis of Magnetic field}

The software COMSOL Multiphysics 5.2 has been used to simulate the magnetic flux density and magnetic force distribution for three cases as shown in Fig. 8. The magnetic flux 
density and the magnetic force distribution are calculated as in https://www.comsol.com and Ref. [26]:

$\vec{B}=\mu_{0} \mu_{\mathrm{r}} \vec{H}+\overrightarrow{B_{\mathrm{r}}}$

$\overrightarrow{F_{\mathrm{M}}}=V_{\mathrm{P}} \frac{\chi_{\mathrm{i}}}{\mu_{0}} \vec{B} \nabla \vec{B}$

where $H$ is the magnetic field, and $B_{\mathrm{r}}$ is the residual magnetic flux density. $B$ is the magnetic flux density. $\mu_{0}$ is the magnetic permeability of the free space, and $\mu_{\mathrm{r}}$ is the relative permeability. $V_{\mathrm{p}}$ is the nanoparticle volume, and $\chi_{\mathrm{i}}$ is the magnetic susceptibility of the magnetite nanoparticles. The magnetic flux density of unsaturated ferromagnetic material lags behind the magnetic field intensity, which is called a phenomenon of hysteresis. When the magnetic field intensity drops to zero, the corresponding magnetic flux density $B$ is called the remnant magnetic flux density $\left(B_{\mathrm{r}}\right)$.

The reliability of the present simulated results is validated by comparisons with results in Ref. [27]. In Fig. 9, it is found that the simulation results show good agreement with the results of reference [27].

The geometric structure in the case I is shown in Fig. 10a. The tube diameter and magnet size in the numerical simulations are consistent with the experimental structure as shown in Fig. 7. A cross section of the pipe $(80 \mathrm{~mm})$ near the magnets is used for simulations. The grid independence study is conducted using $0.86,1.68$ and 3.15 million grid cells as shown in Fig. 10b. By comparing the magnetic flux density along the center line of the pipe in the case with 3.15 million cells, it is found that the case with the 1.68 million cells shows almost no difference. So, the 1.68 million cells are used in this research.

In order to investigate the effect of magnetic field strength, two magnets packaged in a cannula were placed outside the pipe. Figure 11 shows distributions of magnetic flux density $(B)$ on cross planes (Section A-A) through the pipe centerline for case I (one cannula), case II (two adjacent cannulas) and case III (three adjacent cannulas). $B$ between magnets for case I shows a symmetric distribution. The magnetic flux density $(B)$ and magnetic force $\left(F_{\mathrm{m}}\right)$ along the
Fig. 9 Comparison of simulated magnetic flux densities with results in Ref. [29]
Fig. 10 The details of geometry and grid

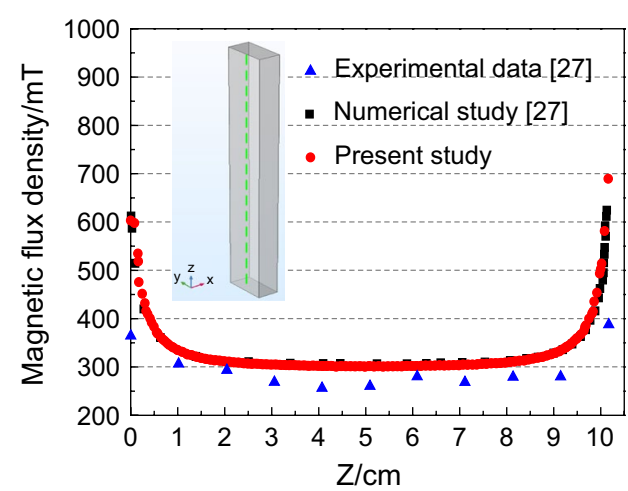

(a) On the surface of a single magnet

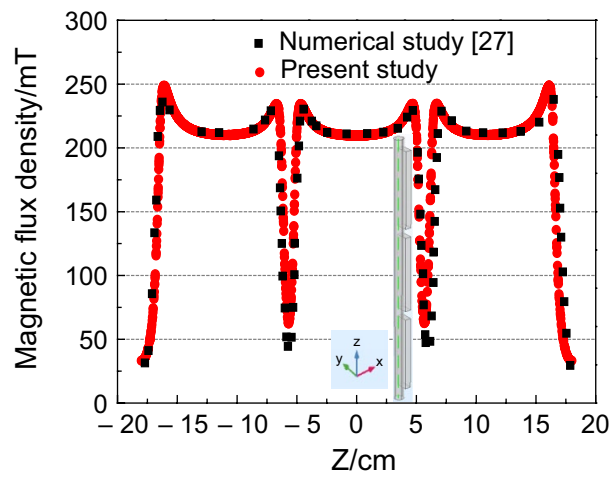

(b) On the center line of the pipe

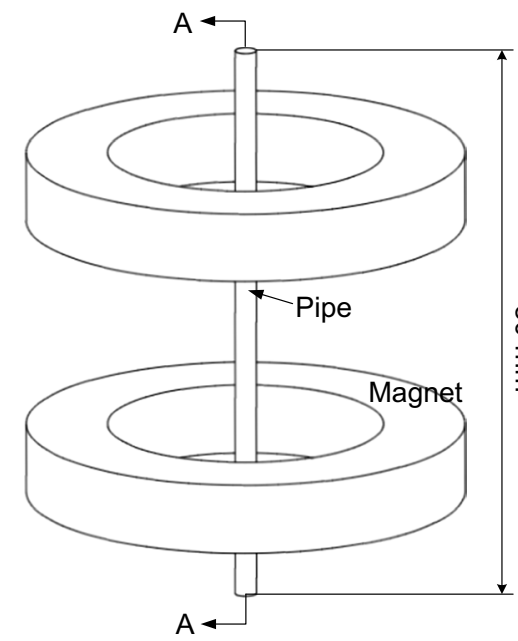

(a) case I

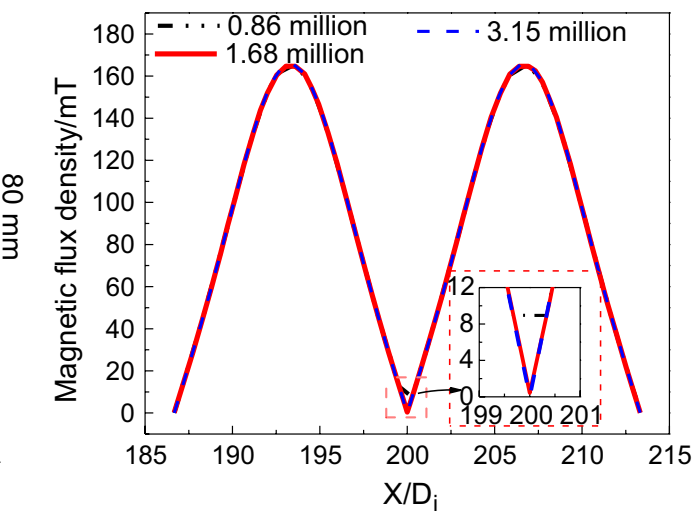

(b) Grid independence 


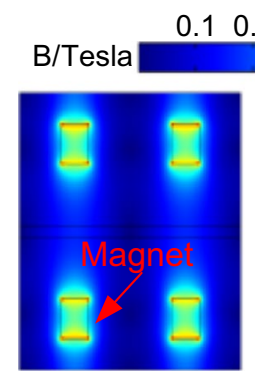

(a) Case I

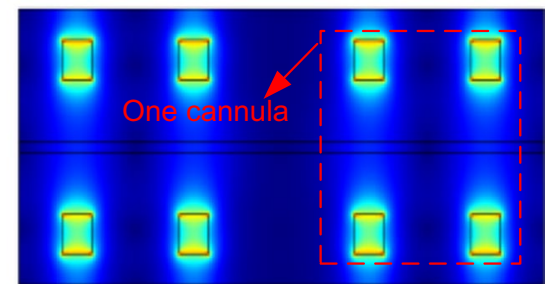

(b) Case II

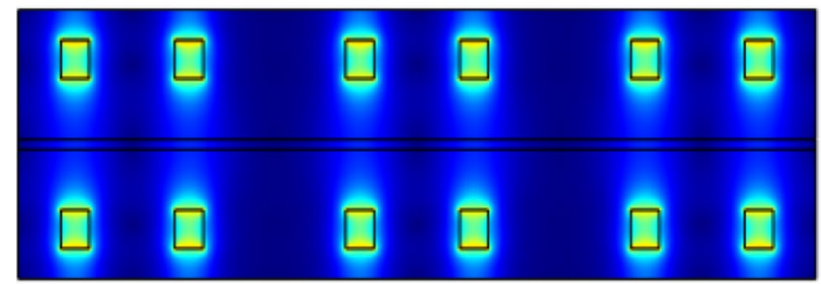

(c) Case III

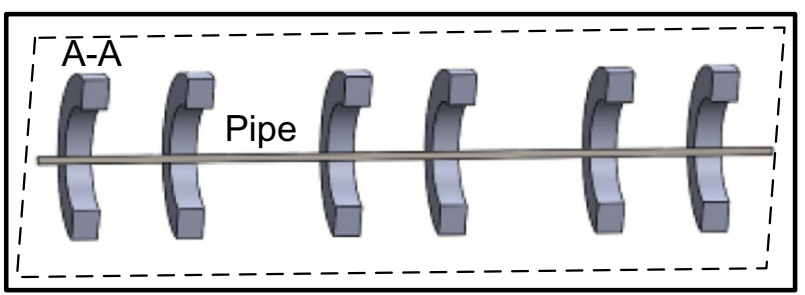

(d) Cross plane A-A

Fig. 11 Magnetic flux density distribution on cross plane (A-A) through pipe centerline for three cases

center line of the pipe are shown in Fig. 12. The magnetic force along the centerline of the pipe has a similar periodic distribution.

The maximum values of $B$ exist near the edges of the magnets as shown in Figs. 11 and 12. It is also proved that large $F_{\mathrm{m}}$ exist at the edges of the magnets (dashed line in Fig. 12) based on a direct relation between magnetic flux density gradient and $F_{\mathrm{m}}$ from Eq. (22). It can be found that the peak values of $B$ for two adjacent cannulas (case II) and three adjacent cannulas (case III) are higher than that for the one cannula (case I).

The $B$ distributions of the magnetic flux density for one cannula, two cannulas and three cannulas show two extremum values, four extremum values and six extremum values, respectively. The maximum values of $B$ and $F_{\mathrm{m}}$ (case II) along the centerline of the pipe are $166.9 \mathrm{mT}$ and $3.68 \times 10^{-17} \mathrm{~N}$, respectively. For case III, the maximum values of $B$ and $F_{\mathrm{m}}$ along the centerline of the pipe are 167.8 $\mathrm{mT}$ and $3.63 \times 10^{-17} \mathrm{~N}$, respectively. It is found that the maximum magnetic force hardly changed in these three cases.

\section{Validation of test data}

In order to verify the reliability of the experimental results, an experimental validation is conducted at various Re numbers $(476,663$ and 996) by using DI-water as the working fluid. The reliability of the experimental data is analyzed based on the results in Fig. 13. It is found that a good agreement between the present experimental data and theoretical values (The error is less than $10 \%$ ) calculated by Eq. (23) in Ref. [28]:

$\mathrm{Nu}= \begin{cases}1.302\left(\frac{x / \mathrm{P}_{\mathrm{P}}}{\operatorname{RePr}}\right)^{-1 / 3}-0.5 & 0.00005 \leq \frac{x / \mathrm{D}_{\mathrm{i}}}{\operatorname{RePr}} \leq 0.0015 \\ 4.364+0.263\left(\frac{x / \mathrm{D}_{\mathrm{i}}}{\operatorname{RePr}}\right)^{-0.506} \mathrm{e}^{-41\left(\frac{x / \mathrm{D}_{\mathrm{i}}}{\operatorname{RePr}}\right)} & \frac{x / \mathrm{D}_{\mathrm{i}}}{\operatorname{RePr}}>0.0015\end{cases}$

Equation (23) is suitable for laminar convective heat transfer under constant heat flux boundary conditions. This equation is widely used to verify reliability of an experimental system [17,27].

\section{Magnetic nanofluid without magnetic field}

Without a magnetic field, Fig. 14 presents the average $\mathrm{Nu}$ of $\mathrm{Fe}_{3} \mathrm{O}_{4}$-water nanofluids and $\mathrm{Fe}_{3} \mathrm{O}_{4}$-CNTs-water hybrid nanofluids at various Re numbers. It is observed that for these nanofluids, the average Nusselt number is higher than that for the base fluid. Moreover, results indicate that the average $\mathrm{Nu}$ of the magnetic nanofluid increases with increases both in $\mathrm{Re}$ and nanoparticle volume fraction. The average $\mathrm{Nu}$ of the $\mathrm{Fe}_{3} \mathrm{O}_{4}$-water nanofluids with volume fractions of $0.4,0.8$ and $1.2 \%$ are $1.96,4.23$ and $5.69 \%$ higher than that of the base fluid at $\mathrm{Re}=476$, respectively. When the Reynolds number is increased to 996, the average Nusselt numbers for the $0.4,0.8$ and $1.2 \%$ nanofluids are $3.65,9.54$ and $13.34 \%$ higher than that of the base fluid, respectively. For the $\mathrm{Fe}_{3} \mathrm{O}_{4}-\mathrm{CNT}$ - - water hybrid nanofluid with 1.32, 1.44 and $1.68 \%$ volume fractions, the average Nusselt number increases by $7.66-14.73 \%, 10.3-17.57 \%$ and $12.56-20.89 \%$ compared to the base fluid under the Reynolds number of 476-996, respectively. These data indicate that the mixture with a small amount of carbon nanotubes can improve the heat transfer performance of the $\mathrm{Fe}_{3} \mathrm{O}_{4}$-water nanofluid.

\section{$\mathrm{Fe}_{3} \mathrm{O}_{4}$-water nanofluid with magnetic field}

For the case I, case II and case III at Reynolds numbers of 476, 663 and 996, Figs. 15-17 show local Nusselt numbers of $\mathrm{Fe}_{3} \mathrm{O}_{4}$-water nanofluids with three volume fractions (0.4, 0.8 and $1.2 \%$ ) along the dimensionless $\mathrm{x}$ axial coordinate $\left(X / D_{\mathrm{i}}\right)$. For the $0.4 \mathrm{vol} \% \mathrm{Fe}_{3} \mathrm{O}_{4}$-water nanofluid, the local Nusselt number $(\mathrm{Nu})$ reaches its maximum value nearly at 
Fig. 12 Magnetic flux density components $\left(B, B_{\mathrm{x}}\right)$ and magnetic force $\left(F_{\mathrm{mx}}\right)$ along the center line of the pipe for three cases

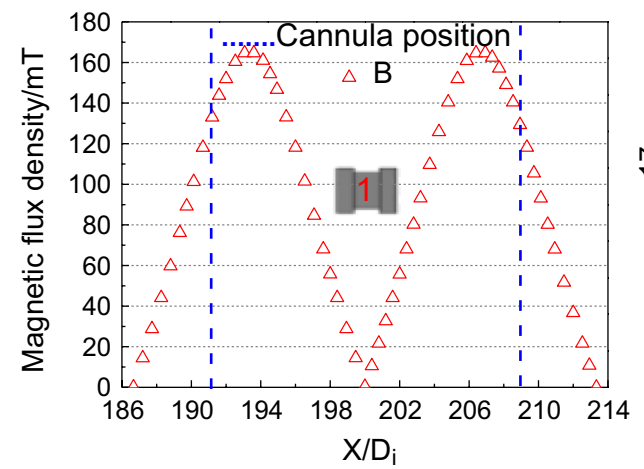

(a) $B$ distribution for case I

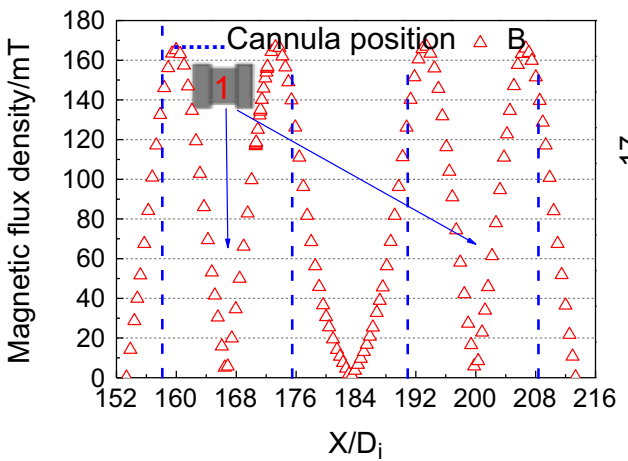

(c) $B$ distribution for case II

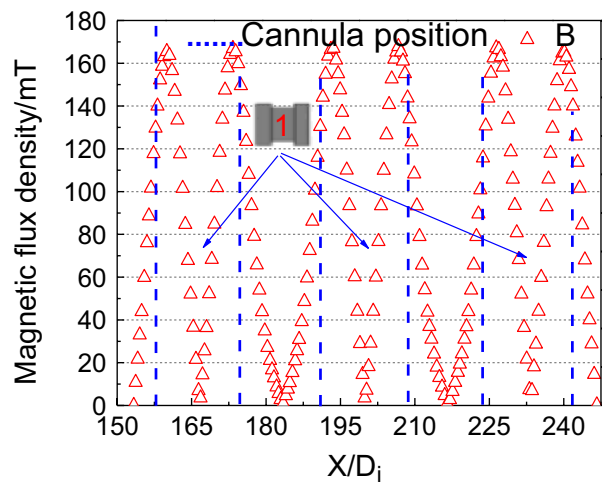

(e) $B$ distribution for case III

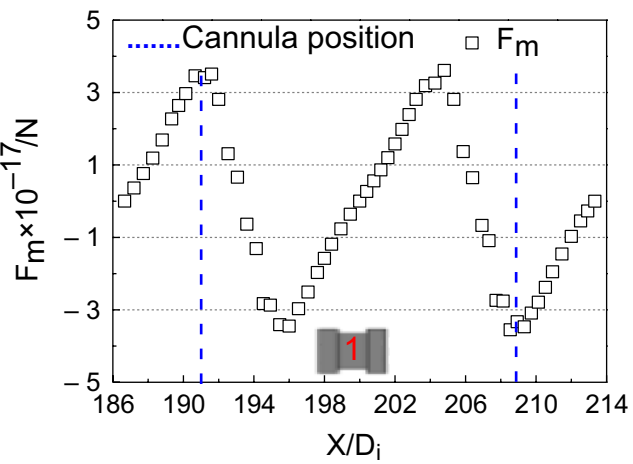

(b) $F_{m}$ distribution for case I

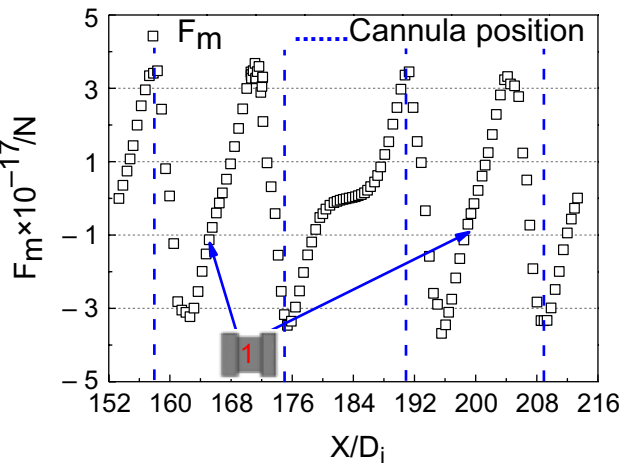

(d) $F_{m}$ distribution for case II

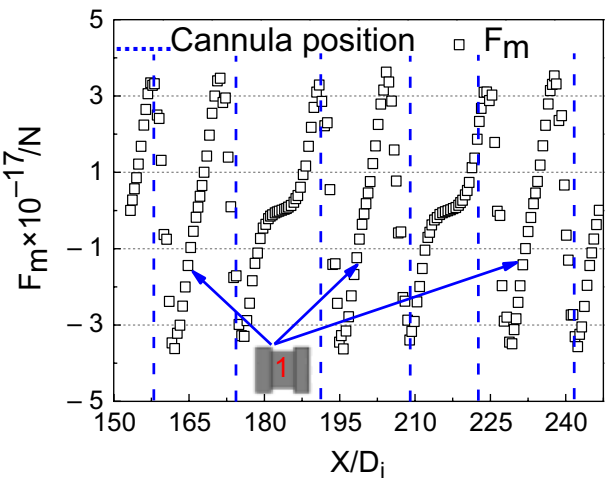

(f) $F_{m}$ distribution for case III the thermocouple number T7 for case I and case II. For case III, the maximum value of $\mathrm{Nu}$ moves from thermocouple number T7 to T8, as the Re increases. For the case III at the same position, the maximum values of local Nusselt numbers for three cases are 31.16, 34.93 and 47.04\% higher than the results without magnetic field at the Reynolds numbers of 476, 663 and 996, respectively. It is found that the presence of the magnetic field results in an enhancement of the convective heat transfer coefficient for all cases at three Reynolds numbers, and three cannulas provides a nearly $50 \%$ enhancement of heat transfer. From the temperature values at the position $\mathrm{T} 9$, it is concluded that the 
Fig. $13 \mathrm{Nu}$ comparison between test results and calculated values from Eq. (23)

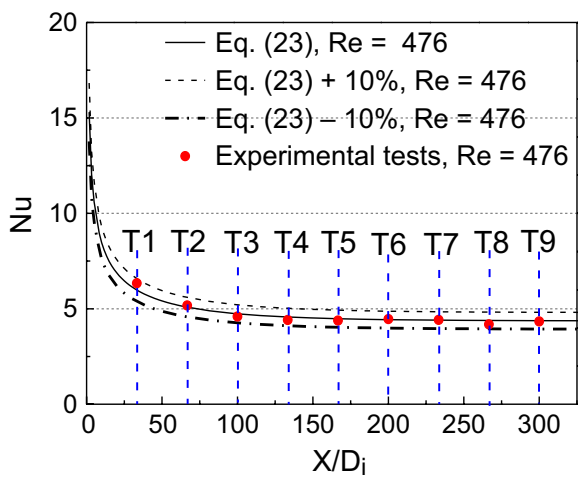

(a) $\operatorname{Re}=476$

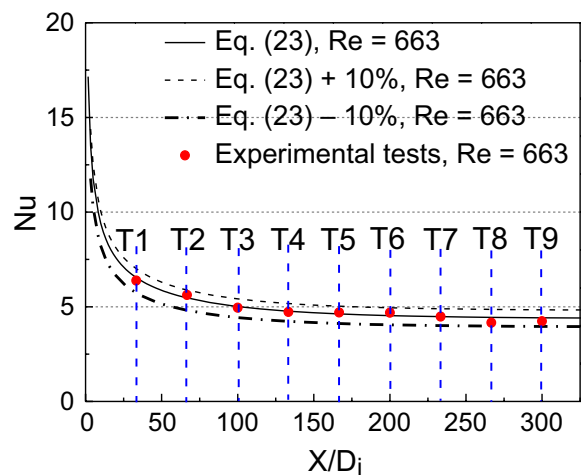

(b) $\operatorname{Re}=663$

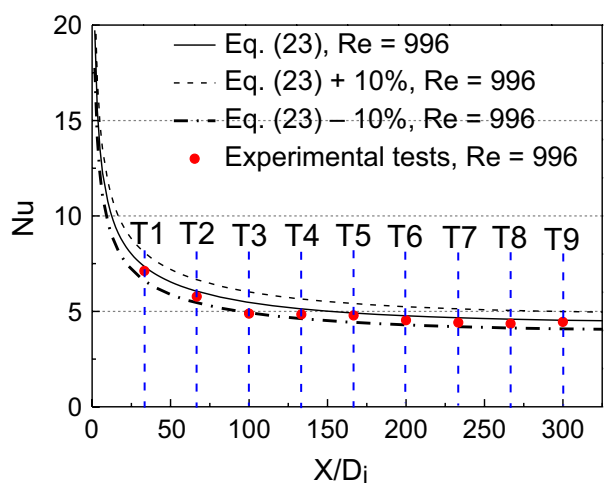

(c) $\operatorname{Re}=996$

heat transfer enhancement is increasing with the increase of the number of magnets, Reynolds number and nanoparticle concentration.

For the 0.8 vol\% $\mathrm{Fe}_{3} \mathrm{O}_{4}$-water nanofluid as shown in Fig. 16, the Nusselt number reaches its maximum value at thermocouple numbers T5-T6. It is found that with the magnetic field, the maximum values of local $\mathrm{Nu}$ for case I, case

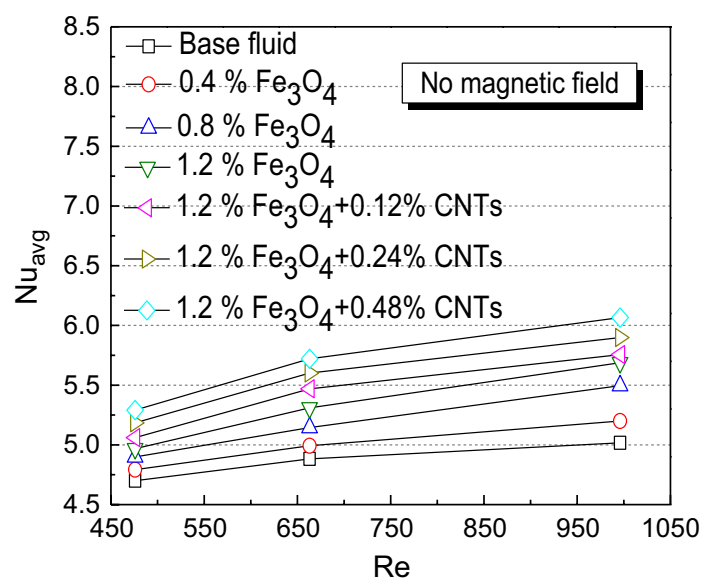

Fig. 14 Average Nusselt numbers for magnetic nanofluids with various volume concentration and Reynolds numbers
II and case III are 33.16, 37.36 and $42.85 \%$ higher than those without a magnetic field at the same position, respectively.

Based on a similar analysis for the $1.2 \mathrm{vol} \% \mathrm{Fe}_{3} \mathrm{O}_{4}$-water nanofluid as shown in Fig. 17, the maximal value of local $N u$ increases by $39.81,53.73$, and $61.13 \%$ for case I, case II and case III, respectively. This is because nanoparticle aggregation has a great effect on enhancement of convective heat transfer. The quantity of aggregated particles on the inner wall of the pipe is rising with the increase of the volume fraction and the intensity of the magnetic field. Larger local thermal conductivity exists near the position of the magnets due to the effect of the magnetic force. In addition, the aggregation of magnetic nanoparticles destroys the wall boundary layer, which enhances the heat transfer near the pipe wall.

\section{$\mathrm{Fe}_{3} \mathrm{O}_{4}-\mathrm{CNTs}$-water nanofluid with magnetic field}

For cases I-III at Reynolds number of 476, 663 and 996, Figs. 18-20 show Nusselt number distributions of $\mathrm{Fe}_{3} \mathrm{O}_{4}$-CNTs-water hybrid nanofluids with three volume fractions $(1.32,1.44$ and $1.68 \%)$ along the dimensionless $\mathrm{x}$ axial coordinate $\left(X / \mathrm{D}_{i}\right)$. It is observed that Nusselt number for cases without magnetic field decreases along the $\mathrm{x}$ axial direction, whereas Nusselt number significantly increases when a magnetic field is applied to the hybrid 
Fig. 15 Variation of Nusselt number vs. dimensionless distance $\left(X / D_{i}\right)$ for 0.4 vol\% $\mathrm{Fe}_{3} \mathrm{O}_{4}$-water nanofluid in three cases

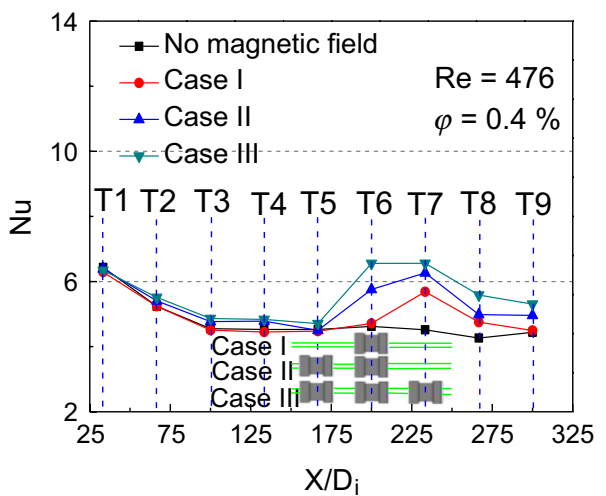

(a) $\operatorname{Re}=476$

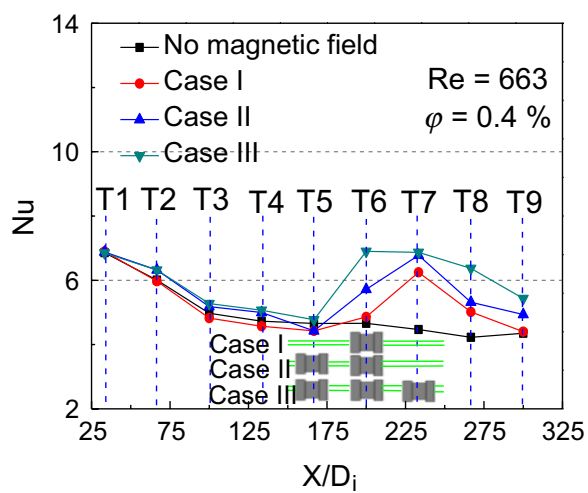

(b) $\operatorname{Re}=663$

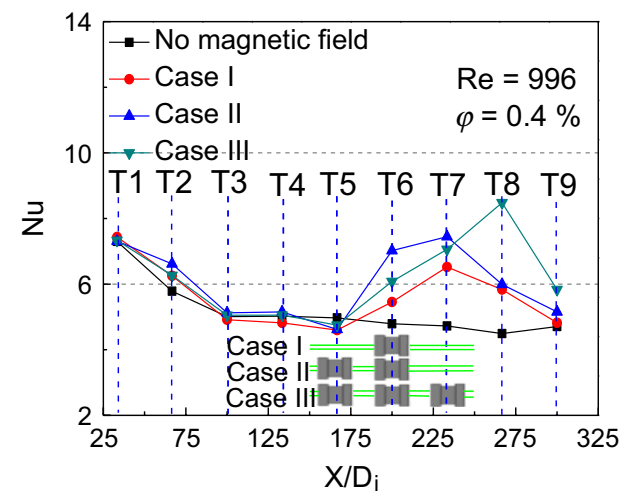

(c) $\operatorname{Re}=996$

nanofluids. For all the Reynolds numbers and with all the volume fractions, the Nusselt number reaches its maximum value at thermocouple positions T6, T6 and T7 for case I, case II and case III, respectively. Compared with the 1.32 vol $\% \mathrm{Fe}_{3} \mathrm{O}_{4}$-CNTs-water nanofluid $\left(1.2 \% \mathrm{Fe}_{3} \mathrm{O}_{4}+0.12 \%\right.$ $\mathrm{CNTs}$ ) at the same position and under no magnetic field, the maximum Nusselt number under three magnetic cannulas increases by $52.57,56.64$ and $59.86 \%$ at Reynolds numbers of 476, 663 and 996, respectively.

For the 1.44 vol\% $\mathrm{Fe}_{3} \mathrm{O}_{4}$-CNTs-water $(1.2 \%$ $\mathrm{Fe}_{3} \mathrm{O}_{4}+0.24 \%$ CNTs) nanofluid at the same position, compared with cases I-III without a magnetic field, it is found that Nusselt numbers of the hybrid nanofluids are improved by $45.57,54.51$ and $61.54 \%$, respectively. For the $1.68 \mathrm{vol} \%$ $\mathrm{Fe}_{3} \mathrm{O}_{4}$-CNTs-water $\left(1.2 \% \mathrm{Fe}_{3} \mathrm{O}_{4}+0.48 \%\right.$ CNTs $)$ nanofluid at the same position, it is found that $\mathrm{Nu}$ of the hybrid nanofluid can be improved by $32.79 \%, 48.74 \%$ and $56.88 \%$, compared with cases I-III under no magnetic field, respectively. It is also revealed that $\mathrm{Nu}$ of hybrid nanofluid with higher volume fraction increases with increasing Re and quantity of cannulas.

As shown in Ref. [29], for the $\mathrm{Fe}_{3} \mathrm{O}_{4}-\mathrm{CNTs}-$ water hybrid nanofluids, a magnetic force changes the distribution and array of the magnetic nanoparticles and the carbon nanotubes, which results in an increased contact area between magnetic nanoparticles and nanotubes. In addition, nanoparticles CNTs and $\mathrm{Fe}_{3} \mathrm{O}_{4}$ under a magnetic field tend to migrate toward the pipe wall. The nanoparticle aggregation will intensify the disturbance of the thermal boundary layer. It is expected that local heat transfer of $\mathrm{Fe}_{3} \mathrm{O}_{4}-\mathrm{CNTs}$-water hybrid nanofluid is higher than for the $\mathrm{Fe}_{3} \mathrm{O}_{4}$-water 
Fig. 16 Variations of Nusselt number vs. dimensionless distance $\left(X / D_{i}\right)$ for 0.8 vol\% $\mathrm{Fe}_{3} \mathrm{O}_{4}$-water nanofluid in three cases

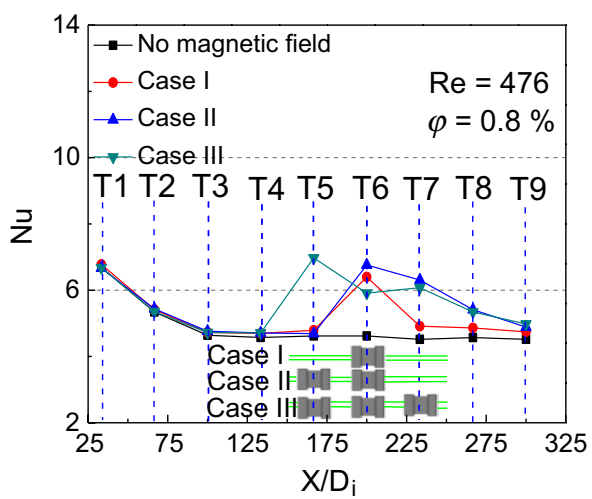

(a) $\operatorname{Re}=476$

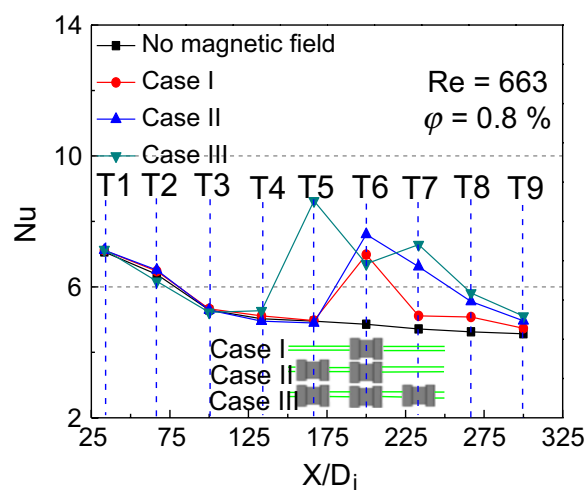

(b) $\operatorname{Re}=663$

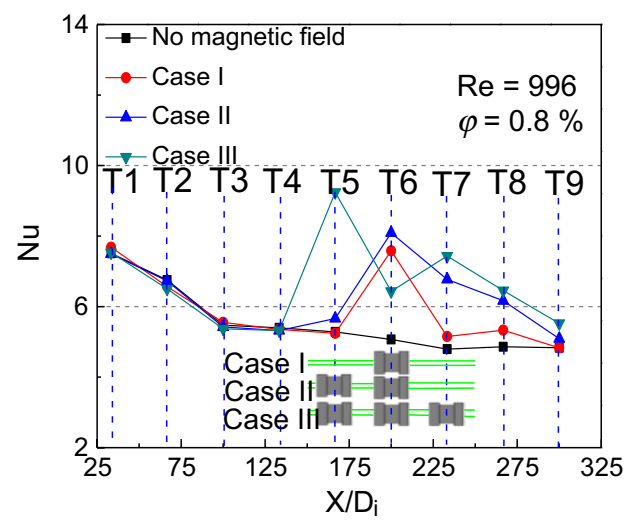

(c) $\operatorname{Re}=996$

nanofluid due to both higher thermal conductivity and destroyed thermal boundary layer.

Table 4 shows improvements of the maximum Nusselt number for cases with various volume fractions and three Reynolds numbers, after three magnetic fields are applied. It is easily found that for the $\mathrm{Fe}_{3} \mathrm{O}_{4}$-water nanofluid, the increase in the number of cannulas results in an enhancement of heat transfer.

For the 1.32 vol\% $\mathrm{Fe}_{3} \mathrm{O}_{4}$-CNTs-water $(1.2 \%$ $\mathrm{Fe}_{3} \mathrm{O}_{4}+0.12 \% \mathrm{CNTs}$ ) nanofluid, the maximum enhancement of the local Nusselt number is higher than for 1.2 vol\% $\mathrm{Fe}_{3} \mathrm{O}_{4}$-water nanofluid in most cases. This result shows that adding a small amount of multi-walled carbon nanotubes into the $\mathrm{Fe}_{3} \mathrm{O}_{4}$-water nanofluid can significantly improve the convective heat transfer in the pipe. This finding is also shown in a study about plate heat exchangers [30]. However, the enhancement in heat transfer for the 1.68 vol\% $\mathrm{Fe}_{3} \mathrm{O}_{4}$-CNTs-water nanofluid is smaller than for the 1.2 vol\% $\mathrm{Fe}_{3} \mathrm{O}_{4}$-water nanofluid in all cases. The reason might be that the viscosity of the $1.68 \mathrm{vol} \%$ $\mathrm{Fe}_{3} \mathrm{O}_{4}$-CNTs-water nanofluid under magnetic field is higher than that of $1.2 \mathrm{vol} \% \mathrm{Fe}_{3} \mathrm{O}_{4}$-water nanofluid, which weakens heat transfer in the pipe. It is easily found that compared with cases under no magnetic field, the increase in the maximum Nusselt number is provided by the 1.44 vol\% $\mathrm{Fe}_{3} \mathrm{O}_{4}$-CNTs-water $\left(1.2 \% \mathrm{Fe}_{3} \mathrm{O}_{4}+0.24 \% \mathrm{CNTs}\right)$ 
Fig. 17 Variations of Nusselt number vs. dimensionless distance $\left(X / D_{i}\right)$ for 1.2 vol\% $\mathrm{Fe}_{3} \mathrm{O}_{4}$-water nanofluid in three cases

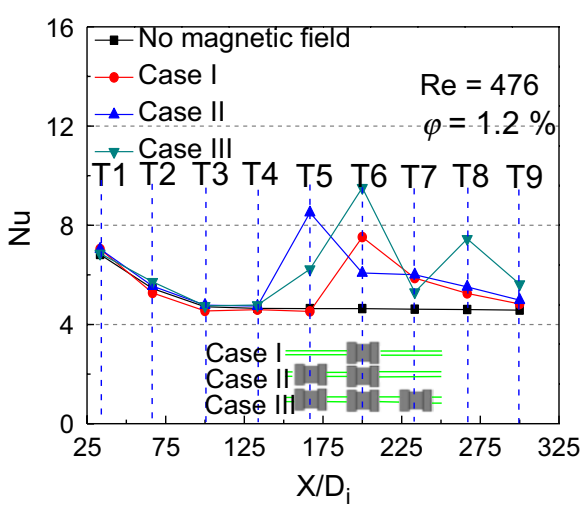

(a) $\operatorname{Re}=476$

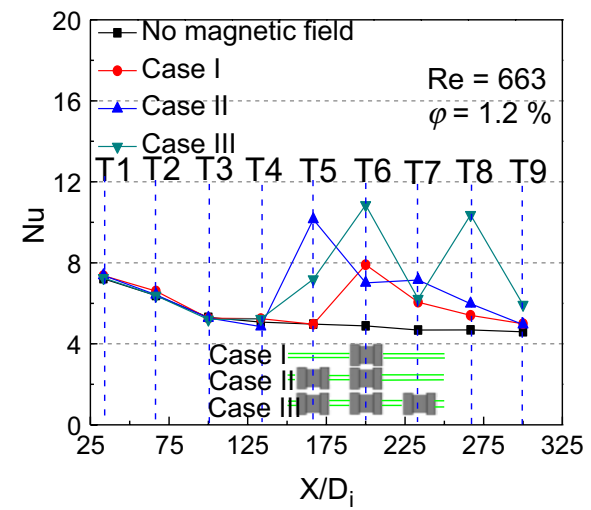

(b) $\operatorname{Re}=663$

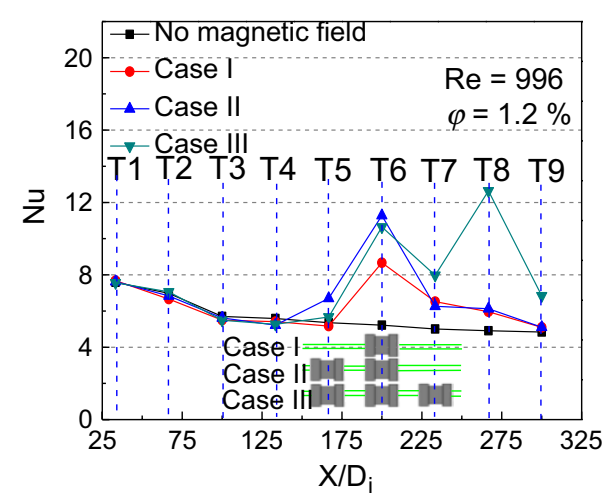

(c) $\operatorname{Re}=996$

hybrid nanofluid under a magnetic field (only exception for two cannula case at $\mathrm{Re}=996$ ).

Improvements of the average Nusselt number for various nanofluids are plotted in Fig. 21. Enhancements for the magnetic cases, volume fractions and Reynolds numbers are shown. Results indicate that without a magnetic field the heat transfer increases with volume fractions and Re. When a magnetic field is applied to the pipe (case I, case II and case III), an optimum volume fraction (1.44 vol\% $\mathrm{Fe}_{3} \mathrm{O}_{4}$-CNTs-water nanofluid) is obtained for each Reynolds number to achieve the maximum heat transfer enhancement. Heat transfer enhancements for the 1.44 vol\% $\mathrm{Fe}_{3} \mathrm{O}_{4}$-CNTs-water nanofluid with a single magnetic cannula (case I) by 26.6, 31.99 and $34.85 \%$ are found at $\mathrm{Re}=476,663$ and 996, respectively. Compared with the 1.44 vol\% $\mathrm{Fe}_{3} \mathrm{O}_{4}-\mathrm{CNTs}-$ water nanofluid with double magnetic cannulas (case II), the average Nusselt number enhancement at the Reynolds number of 663 is higher than at the Reynolds number of 996. It is found that the maximum improvement of $67.9 \%$ of heat transfer is achieved by a dispersion of $1.44 \mathrm{vol} \%$ nanoparticles inside the DIwater at high Reynolds number with three magnetic cannulas (case III). 
Fig. 18 Variations of Nusselt number vs. dimensionless distance $\left(X / D_{i}\right)$ for $1.32 \mathrm{vol} \%$ $\mathrm{Fe}_{3} \mathrm{O}_{4}$-CNTs-water $(1.2 \%$ $\mathrm{Fe}_{3} \mathrm{O}_{4}+0.12 \%$ CNTs) nanofluid in three cases

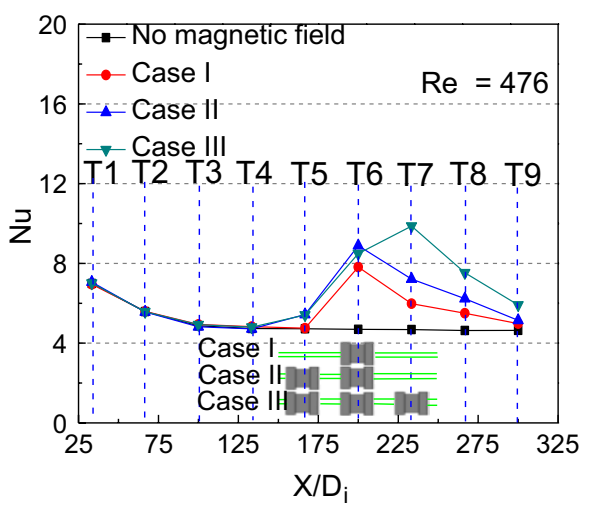

(a) $\operatorname{Re}=476$

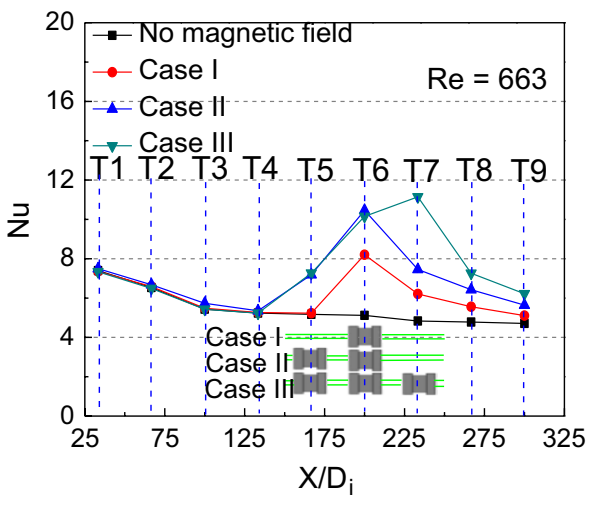

(b) $\operatorname{Re}=663$

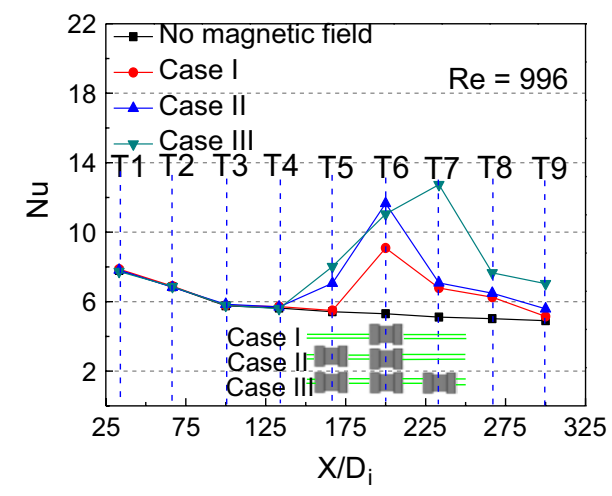

(c) $\operatorname{Re}=996$ 
Fig. 19 Variations of Nusselt number vs. dimensionless distance $\left(X / D_{\mathrm{i}}\right)$ for $1.44 \mathrm{vol} \%$ $\mathrm{Fe}_{3} \mathrm{O}_{4}-\mathrm{CNTs}-$ water $(1.2 \%$ $\mathrm{Fe}_{3} \mathrm{O}_{4}+0.24 \% \mathrm{CNTs}$ ) nanofluid in three cases

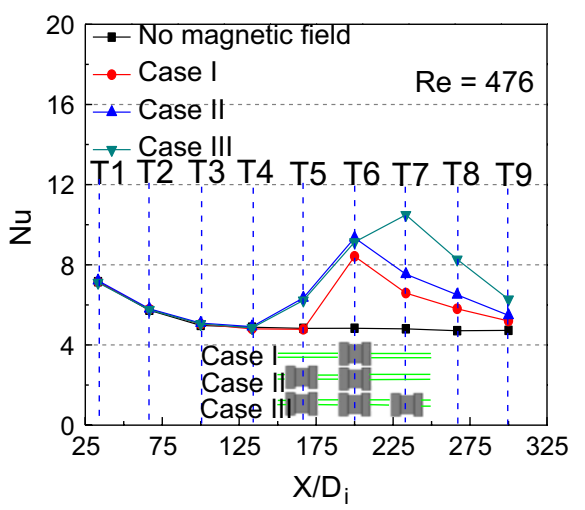

(a) $\operatorname{Re}=476$

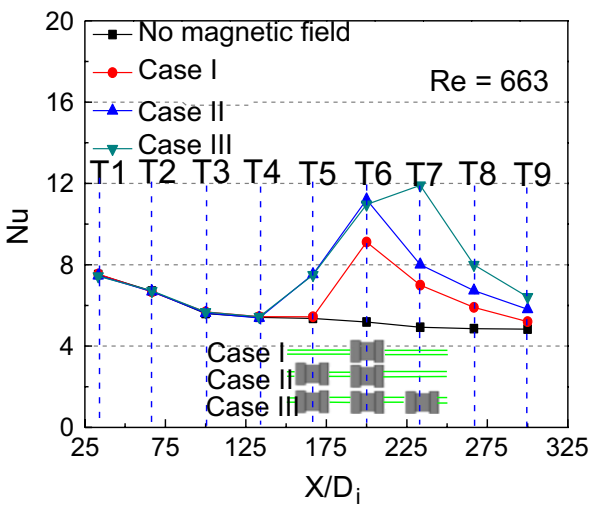

(b) $\mathrm{Re}=663$

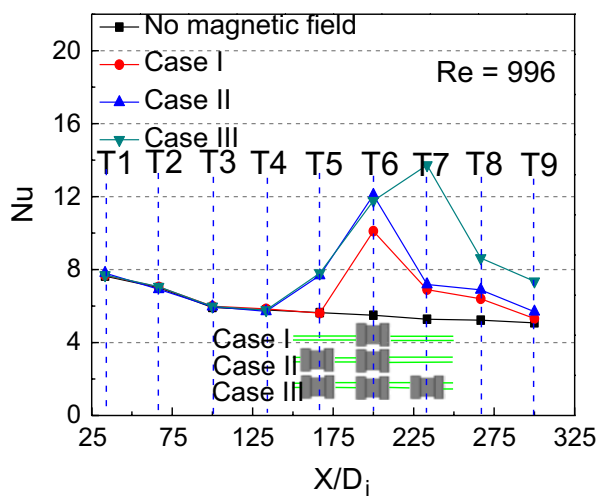

(c) $\operatorname{Re}=996$

Fig. 20 Variations of Nusselt number vs. dimensionless distance $\left(X / D_{\mathrm{i}}\right)$ for $1.68 \mathrm{vol} \%$ $\mathrm{Fe}_{3} \mathrm{O}_{4}-\mathrm{CNTs}$-water $(1.2 \%$ $\mathrm{Fe}_{3} \mathrm{O}_{4}+0.48 \%$ CNTs) nanofluid in three cases

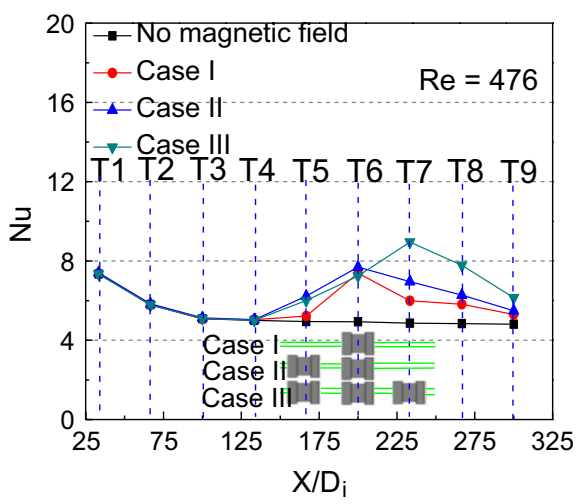

(a) $\operatorname{Re}=476$

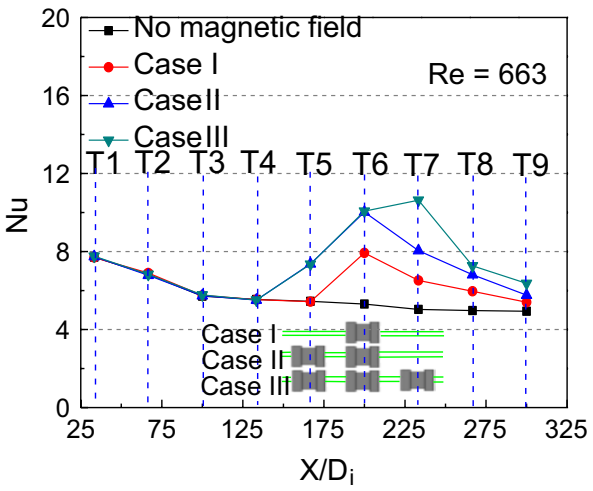

(b) $\mathrm{Re}=663$

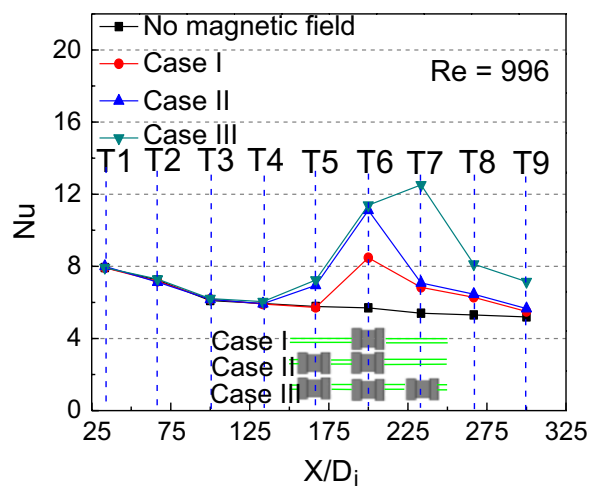

(c) $\mathrm{Re}=996$ 
Table 4 Comparisons of the maximum Nusselt number for various nanofluids with and without magnetic field

\begin{tabular}{|c|c|c|c|c|c|c|}
\hline & $0.4 \% \mathrm{Fe}_{3} \mathrm{O}_{4} / \%$ & $0.8 \% \mathrm{Fe}_{3} \mathrm{O}_{4} / \%$ & $1.2 \% \mathrm{Fe}_{3} \mathrm{O}_{4} / \%$ & $\begin{array}{l}1.32 \% \\
\mathrm{Fe}_{3} \mathrm{O}_{4}+\mathrm{CNTs} / \%\end{array}$ & $\begin{array}{l}1.44 \% \\
\mathrm{Fe}_{3} \mathrm{O}_{4}+\mathrm{CNTs} / \%\end{array}$ & $\begin{array}{l}1.68 \% \\
\mathrm{Fe}_{3} \mathrm{O}_{4}+\mathrm{CNTs} / \%\end{array}$ \\
\hline Case I, $\mathrm{Re}=446$ & 20.57 & 27.82 & 38.3 & 39.97 & 42.57 & 33.24 \\
\hline Case II, $\mathrm{Re}=446$ & 27.91 & 31.68 & 45.46 & 47.21 & 48.24 & 35.91 \\
\hline Case III, $\mathrm{Re}=446$ & 31.16 & 33.78 & 51.21 & 52.57 & 54.21 & 45.67 \\
\hline Case I, $R e=663$ & 28.48 & 30.45 & 38.24 & 37.6 & 43.11 & 33.07 \\
\hline Case II, $\mathrm{Re}=663$ & 34.05 & 36.1 & 51.02 & 51.09 & 53.72 & 47.05 \\
\hline Case III, $\mathrm{Re}=663$ & 34.93 & 42.58 & 55.01 & 56.64 & 58.61 & 52.67 \\
\hline Case I, $R e=996$ & 27.55 & 33.16 & 39.81 & 41.66 & 45.57 & 32.79 \\
\hline Case II, $\mathrm{Re}=996$ & 36.55 & 37.36 & 53.73 & 54.52 & 54.51 & 48.74 \\
\hline Case III, $\mathrm{Re}=996$ & 47.04 & 42.85 & 61.13 & 59.86 & 61.54 & 56.88 \\
\hline
\end{tabular}

Fig. $21 \mathrm{Nu}$ enhancement of various magnetic nanofluids vs. Reynolds number and volume concentration

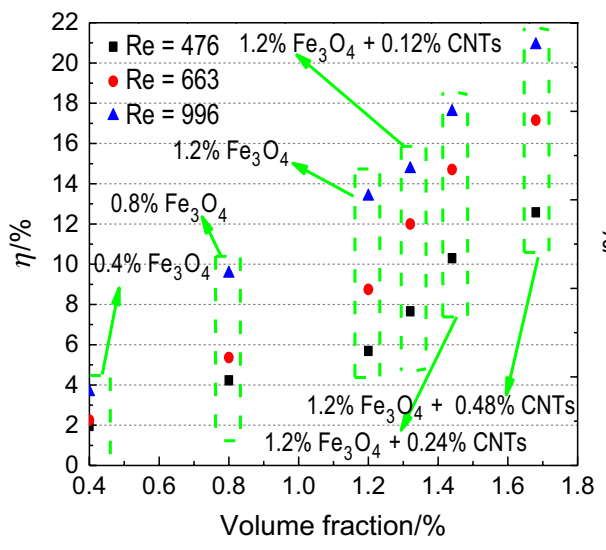

(a) No magnetic field

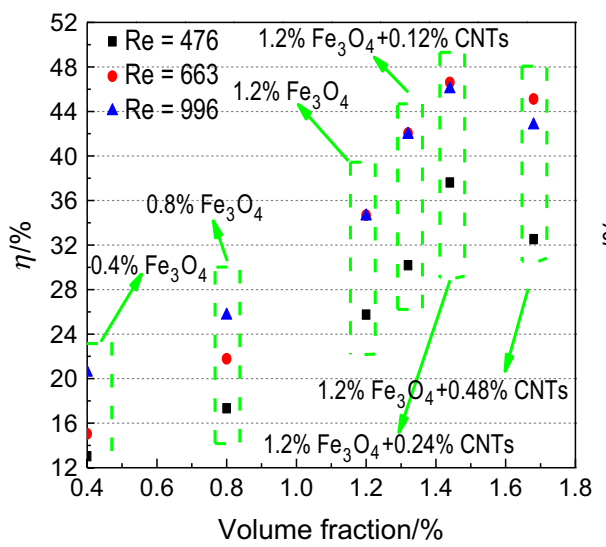

(c) Case II

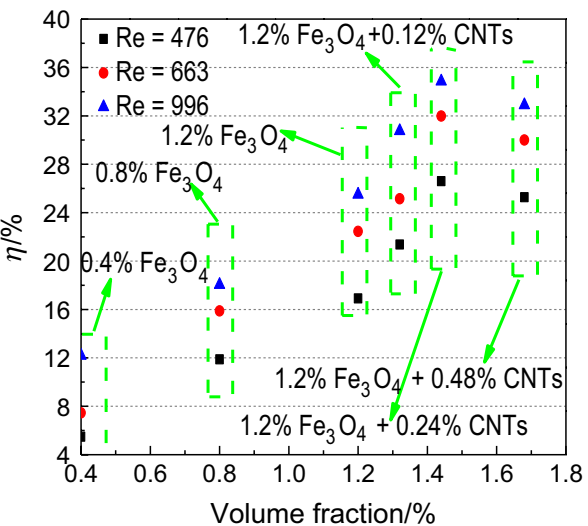

(b) Case I

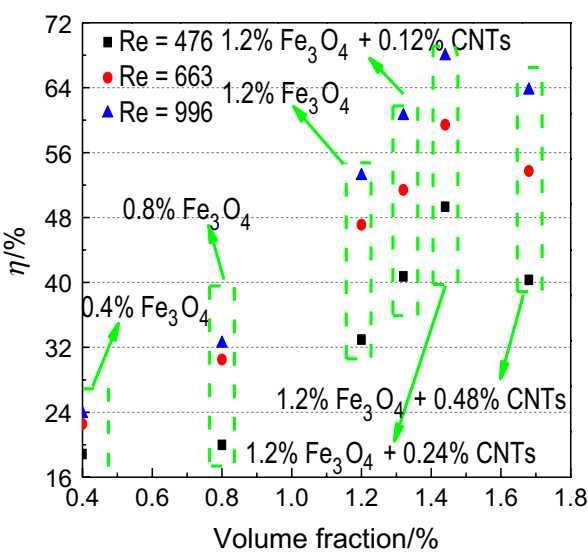

(d) Case III

\section{Conclusions}

In this study, various volume fractions of nanoparticles $\mathrm{Fe}_{3} \mathrm{O}_{4}$ and carbon nanotubes (CNTs) were used to improve the thermophysical properties of the base fluid. Heat transfer characteristics of a $\mathrm{Fe}_{3} \mathrm{O}_{4}-\mathrm{CNTs}$-water hybrid nanofluid in a heated straight pipe were experimentally investigated and compared with $\mathrm{Fe}_{3} \mathrm{O}_{4}$-water nanofluid under magnetic field arrangement and for various Reynolds numbers.

For the $1.2 \mathrm{vol} \% \mathrm{Fe}_{3} \mathrm{O}_{4}$-water nanofluid, the maximal values of the local Nusselt number increased by 39.81, 53.73, and $61.13 \%$ for cases with one cannula, two cannulas and three cannulas, respectively. Compared with $\mathrm{Fe}_{3} \mathrm{O}_{4}$-water nanofluid without magnetic field, the heat transfer performance can be significantly improved by increasing the number of magnetic cannulas. When $0.12 \%$ carbon nanotubes are added into $1.2 \%$ 
$\mathrm{Fe}_{3} \mathrm{O}_{4}$-water nanofluid, the maximum enhancement of the local Nusselt number is increased. Compared with cases under no magnetic field, a nanofluid with $1.2 \% \mathrm{Fe}_{3} \mathrm{O}_{4}$ nanoparticles and $0.24 \%$ carbon nanotubes shows the maximum Nusselt number under a magnetic field in most cases.

The presence of the magnetic field improves the convective heat transfer in the pipe due to the increase in thermal conductivity, the enhancement of turbulence, and the disturbance of the thermal boundary layer. The hybrid magnetic nanofluid might be a potential cooling medium for further enhancement of the heat transfer performance.

Acknowledgements This work is supported by the National Natural Science Foundation of China (Grant No. 51576059) and the Project of Innovation Ability Training for Postgraduate Students of Education Department of Hebei Province (Grant No. CXZZSS2019012).

Funding Open access funding provided by Lund University.

Open Access This article is licensed under a Creative Commons Attribution 4.0 International License, which permits use, sharing, adaptation, distribution and reproduction in any medium or format, as long as you give appropriate credit to the original author(s) and the source, provide a link to the Creative Commons licence, and indicate if changes were made. The images or other third party material in this article are included in the article's Creative Commons licence, unless indicated otherwise in a credit line to the material. If material is not included in the article's Creative Commons licence and your intended use is not permitted by statutory regulation or exceeds the permitted use, you will need to obtain permission directly from the copyright holder. To view a copy of this licence, visit http://creativecommons.org/licenses/by/4.0/.

\section{References}

1. Ali HM, Ali H, Liaquat H, Maqsood HTB, Nadir MA. Experimental investigation of convective heat transfer augmentation for car radiator using ZnO-water nanofluids. Energy. 2015;84:317-24.

2. Sajid MU, Ali HM, Sufyan A, Rashid D, Zahid SU, Rehman WU. Experimental investigation of $\mathrm{TiO}_{2}$-water nanofluid flow and heat transfer inside wavy mini-channel heat sinks. J Therm Anal Calorim. 2019;137:1279-94.

3. Ebrahimi AE, Rikhtegar F, Sabaghan A, Roohi E. Heat transfer and entropy generation in a microchannel with longitudinal vortex generators using nanofluids. Energy. 2016;101:190-201.

4. Shanbedi M, Amiri A, Heris SZ, Eshghi H, Yarmand H. Effect of magnetic field on thermo-physical and hydrodynamic properties of different metals-decorated multi-walled carbon nanotubesbased water coolants in a closed conduit. J Therm Anal Calorim. 2018;131:1089-106.

5. Zheng D, Yang J, Wang J, Kabelac S, Sundén B. Analyses of thermal performance and pressure drop in a plate heat exchanger filled with ferrofluids under a magnetic field. Fuel. 2021;293:120432.

6. Kumar PCM, Chandrasekar M. Heat transfer and friction factor analysis of MWCNT nanofluids in double helically coiled tube heat exchanger. J Therm Anal Calorim. 2020. https://doi.org/10.1007/ s10973-020-09444-X.

7. Dabiri E, Bahrami F, Mohammadzadeh S. Experimental investigation on turbulent convection heat transfer of $\mathrm{SiC} / \mathrm{W}$ and $\mathrm{MgO} / \mathrm{W}$ nanofluids in a circular tube under constant heat flux boundary condition. J Therm Anal Calorim. 2018;131:2243-59.
8. Sarafraz MM, Hormozi F, Nikkhah V. Thermal performance of a counter-current double pipe heat exchanger working with $\mathrm{COOH}-$ CNT/water nanofluids. Exp Therm Fluid Sci. 2016;78:41-9.

9. Hosseinipour E, Heris SZ, Shanbedi M. Experimental investigation of pressure drop and heat transfer performance of amino acid-functionalized MWCNT in the circular tube. J Therm Anal Calorim. 2016;124:205-14.

10. Shahsavar A, Godini A, Sardari PT, Toghraie D, Salehipour H. Impact of variable fluid properties on forced convection of $\mathrm{Fe}_{3} \mathrm{O}_{4} /$ $\mathrm{CNT} /$ water hybrid nanofluid in a double-pipe mini-channel heat exchanger. J Therm Anal Calorim. 2019;137:1031-43.

11. Moreira LM, Carvalho EA, Bell MJV, Anjos V, Sant'Ana C, Alves APP, Fragneaud B, Sena LA, Archanjo BS, Achete CA. Thermooptical properties of silver and gold nanofluids. J Therm Anal Calorim. 2013;114:557-64.

12. Wang J, Li G, Zhu H, Luo J, Sundén B. Experimental investigation on convective heat transfer of ferrofluids inside a pipe under various magnet orientations. Int J Heat Mass Tran. 2019;132:407-19.

13. Hosseinzadeh M, Heris SZ, Beheshti A, Shanbedi M. Convective heat transfer and friction factor of aqueous $\mathrm{Fe}_{3} \mathrm{O}_{4}$ nanofluid flow under laminar regime. J Therm Anal Calorim. 2016;124:827-38.

14. Goharkhah M, Ashjaee M, Shahabadi M. Experimental investigation on convective heat transfer and hydrodynamic characteristics of magnetite nanofluid under the influence of an alternating magnetic field. Int J Therm Sci. 2016;99:113-24.

15. Asfer M, Mehta B, Kumar A, Khandekar S, Panigrahi PK. Effect of magnetic field on laminar convective heat transfer characteristics of ferrofluid flowing through a circular stainless steel tube. Int J Heat Fluid Fl. 2016;59:74-86.

16. Li Q, Xuan Y. Experimental investigation on heat transfer characteristics of magnetic fluid flow around a fine wire under the influence of an external magnetic field. Exp Therm Fluid Sci. 2009;33:591-6.

17. Shahsavar A, Saghafian M, Salimpour MR, Shafii MB. Experimental investigation on laminar forced convective heat transfer of ferrofluid loaded with carbon nanotubes under constant and alternating magnetic fields. Exp Therm Fluid Sci. 2016;76:1-11.

18. Harandi SS, Karimipour A, Afrand M, Akbari M, D'Orazio A. An experimental study on thermal conductivity of F-MWCNTs- $\mathrm{Fe}_{3} \mathrm{O}_{4} /$ EG hybrid nanofluid: effects of temperature and concentration. Int Commun Heat Mass Tran. 2016;76:171-7.

19. Askari S, Koolivand H, Pourkhalil M, Lotfi R, Rashidi A. Investigation of $\mathrm{Fe}_{3} \mathrm{O}_{4} / \mathrm{Graphene}$ nanohybrid heat transfer properties: Experimental approach. Int Commun Heat Mass Tran. 2017;87:30-9.

20. Askari S, Lotfi R, Rashidi AM, Koolivand H, Koolivand-Salooki M. Rheological and thermophysical properties of ultra-stable kerosenebased $\mathrm{Fe}_{3} \mathrm{O}_{4} /$ Graphene nanofluids for energy conservation. Energ Convers Manage. 2016;128:134-44.

21. Nadooshan AA, Eshgarf $\mathrm{H}$, Afrand $\mathrm{M}$. Measuring the viscosity of $\mathrm{Fe}_{3} \mathrm{O}_{4}$-MWCNTs/EG hybrid nanofluid for evaluation of thermal efficiency: Newtonian and non-Newtonian behavior. J Mol Liq. 2018;583:169-77.

22. Farbod M, Ahangarpour A. Improved thermal conductivity of Ag decorated carbon nanotubes water based nanofluids. Phys Lett A. 2016;380:4044-8.

23. Usman M, Hamid M, Zubair T, Haq RU, Wang W. $\mathrm{Cu}-\mathrm{Al}_{2} \mathrm{O}_{3}$ /Water hybrid nanofluid through a permeable surface in the presence of nonlinear radiation and variable thermal conductivity via LSM. Int J Heat Mass Tran. 2018;126:1347-56.

24. Einstein A. Investigations on the theory of the Brownian movement. New York: Dover Publications; 1956.

25. Moffat RJ. Describing uncertainties in experimental results. Exp Therm Fluid Sci. 1988;1:3-17.

26. Pankhurst QA, Connolly J, Jones SK, Dobson J. Applications of magnetic nanoparticles in biomedicine. J Phys D Appl Phys. 2003;36:R167-81. 
27. Azizian R, Doroodchi E, Mckrell T, Buongiorno J, Hu LW. Effect of magnetic field on laminar convective heat transfer of magnetite nanofluids. Int J Heat Mass Tran. 2014;68:94-109.

28. Lienhard IV, Lienhard V. A heat transfer textbook. 4th ed. Phlogiston Press; 2011.

29. Horton M, Hong H, Li C, Shi B, Peterson GP, Jin S. Magnetic alignment of Ni-coated single wall carbon nanotubes in heat transfer nanofluids. J Appl Phys. 2010;107:104320-1-104320-4.
30. Huang D, Wu Z, Sunden B. Effects of hybrid nanofluid mixture in plate heat exchangers. Exp Therm Fluid Sci. 2016;72:190-6.

Publisher's Note Springer Nature remains neutral with regard to jurisdictional claims in published maps and institutional affiliations. 